\title{
FT-IR and Raman vibrational microspectroscopies used for spectral biodiagnosis of human tissues
}

\author{
Shan-Yang Lin *, Mei-Jane Li and Wen-Ting Cheng \\ Biopharmaceutics Laboratory, Department of Medical Research \& Education, Taipei Veterans General \\ Hospital, Taipei, Taiwan, Republic of China
}

\begin{abstract}
Fourier transform infrared (FT-IR) and Raman vibrational microspectroscopies used for biomedical diagnosis of human tissues are reviewed from basic principle to biological applications. The advantages and disadvantages of both vibrational microspectroscopies are compared to highlight their efficiency and adaptability for noninvasively investigating the chemical compositions of ultrastructual human tissues at different disease states. Biochemical fingerprints applied to the biological samples by using FT-IR and Raman microspectroscopies are illustrated. The spectral biodiagnoses of several diseased human tissues such as ophthalmic disorders (risk factors-induced cataractous lens capsules and lens, lens and corneal calcifications, opacification and contamination of intraocular lens, vitreous asteroid bodies), alcohol-disordered human gastric mucosa, skin disorders (cancer and calcification), brain tumors (pituitary adenomas and astrocytomas), genetic hair roots disorder (glucose-6-phosphate dehydrogenase deficiency, phenylketonuria and congenital hypothyroidism), benign prostatic hyperplasia, and interstitial cystitis investigated by both vibrational microspectroscopies in our laboratory are introduced.
\end{abstract}

Keywords: FT-IR, Raman, microspectroscopy, spectral diagnosis, human tissues

\section{Introduction}

Infrared (IR) and Raman spectroscopies have been widely applied to detect the vibrational characteristics of chemical functional groups in diverse materials, including polymers, semiconductors, pharmaceuticals, and others [1-4]. Both techniques not only provide the chemical information for all materials but also offer chemical fingerprinting services for different analytical results, particularly after the Fourier transform (FT) system has been introduced into both techniques. A FT infrared (FT-IR) spectrometer collects an interferogram of a sample signal from an interferometer to obtain the IR spectrum of sample, while FT-Raman spectroscopy uses a laser beam to illuminate the sample and collects Raman scattering from a sample [5]. These FT instruments equipped with a computer system enable weak signals to be measured faster and more sensitive than the older dispersive instruments. The computerized FT instrument may save the IR or Raman spectrum of sample for different data processings.

\footnotetext{
* Corresponding author: Prof. Shan-Yang Lin, PhD, Department of Medical Research and Education, Taipei Veterans General Hospital, Taipei, Taiwan, Republic of China. Tel.: +88622875 7397; Fax: +88622873 7200; E-mail: sylin@vghtpe. gov.tw.
} 

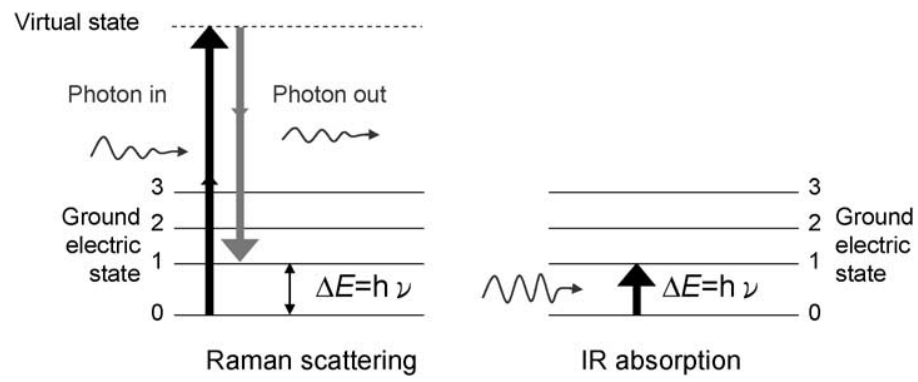

Fig. 1. Virtual energy levels for IR and Raman spectroscopy.

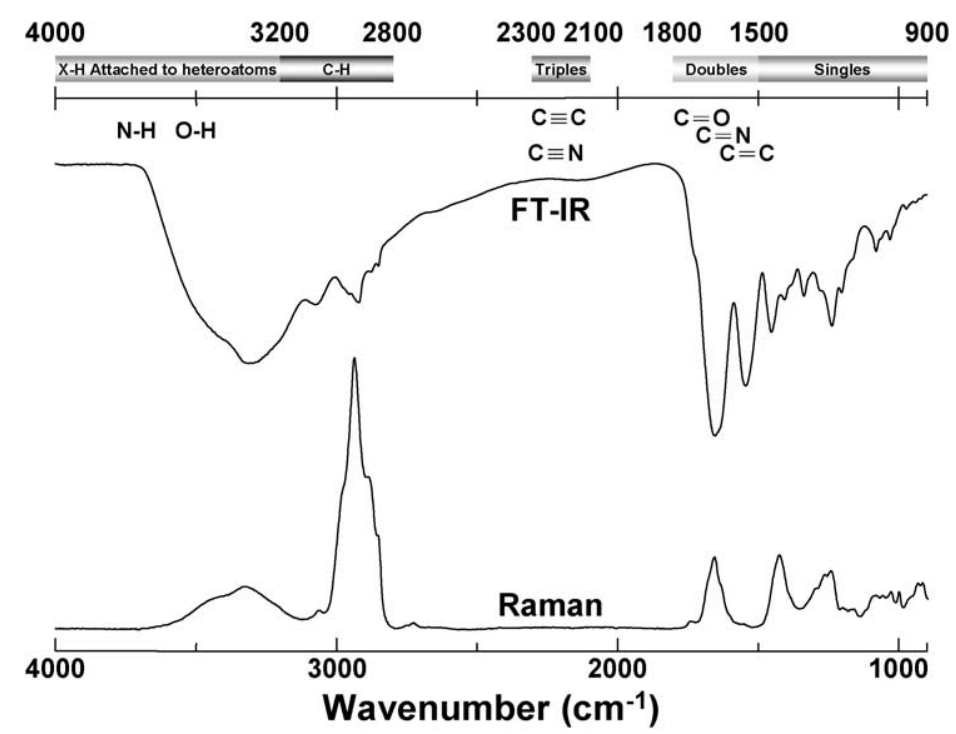

Fig. 2. Typical FT-IR and Raman spectra of collagen.

Thus, it is interesting for many researchers in the fields of biochemistry, biomedicine, biophysics and biomaterials to use both vibrational spectroscopies to investigate structural components of biosamples [6-8].

Although IR and Raman spectroscopies measure the vibrational energies of molecules, both methods are dependent on different selection rules, i.e., an absorption process and a scattering effect (Fig. 1). IR spectroscopy is based on the absorption of electromagnetic radiation, whereas Raman spectroscopy relies upon inelastic scattering of electromagnetic radiation. The sample is radiated by IR light in IR spectroscopy, and the vibrations induced by electrical dipole moment are detected. In Raman spectroscopy, the sample is illuminated by a monochromatic visible or near IR light from a laser source and its vibrations during the electrical polarisability changes are determined [5,8,9]. Thus both vibrational techniques may provide complementary information, since the shapes and positions of both spectral bands on the energy scale are closely located for the specific functional groups of the molecule (Fig. 2). Many vibrations are observed in both spectra to serve as a valuable confirmatory evidence of samples. Therefore, the combination of using IR and Raman spectroscopies can offer a more potential approach for analyzing intact sample and provides more detailed chemical information. 


\section{FT-IR or Raman microscopy and imaging}

Recently, FT-IR or Raman spectroscopy is coupled with a microscope and a computer system, capable of microanalysis of minute samples by using a dedicated detector, mercury cadmium telluride (MCT). The resultant FT-IR or Raman vibrational microspectroscopy can provide molecular information of samples with a high spatial resolution at microscopic level. Samples with microscopic size can be nondestructively analyzed by both vibrational microspectroscopies, particularly in the application of biomedical sciences [10-13]. Thus, the use of both vibrational microspectroscopies have extensively become a great potential over other diagnostic techniques for noninvasively investigating the chemical components of ultrastructual tissues at various disease states, due to the reagentless procedure and no dyes or labels addition for spectral determination $[6,14,15]$. As compared with conventional histopathologic diagnosis, the microspectroscopic chemical information is admitted to be more objective and rapid. Both microspectroscopic techniques not only provide more detailed spectral information of tissue (lipids, proteins, RNA/DNA, carbohydrates) for physicians, but also earlier predict the diagnostic results of diseases. In the current biomedical diagnosis, many investigations have been focused on discriminating normal and malignant tissues at different sites such as oral, stomach, cervical, breast, and skin, colon, etc. $[10,12,14]$. Several excellent review papers to introduce the biomedical applications of FT-IR and Raman microspectroscopies have been reported [6-8,11-14,16-18].

More recently, FT-IR and/or Raman microspectroscopic imaging systems have also been developed for applying to biosciences [19-23]. The imaging system is a powerful tool to map the spatial compositions distributed in the heterogeneous biological tissues. With the development of new software and instrument, functional group mapping or chemical imaging has become accessible. In common, the spectroscopic images are obtained by mapping with a standard microscope equipped with an XY stage and a computer-controlled motorized stage, but this process is time consuming even to map a few square millimeters in size. FT-IR or Raman spectra may be simultaneously collected at a time in a stepwise manner from different areas of a sample. The absorbance of a band corresponding to a specific chemical component may be plotted as a map. A new imaging capability has been established not only to image heterogeneous regions of tissue and simultaneously to provide spectroscopic and spatial information, but also to show visually the concentrations of components and to highlight their effect from the threedimensional plot. The application of microscopic FT-IR imaging system to the intestinal section of SD rats after feeding either cholesterol alone (A) or cholesterol and the Ginkgo biloba L. extracts (B) is shown in Fig. 3, in which the absorbance images represent the area under the IR peaks at $2917 \mathrm{~cm}^{-1}$ (lipid), $1655 \mathrm{~cm}^{-1}$ (protein) and $1081 \mathrm{~cm}^{-1}$ (phosphate and glycogen) of a $5 \mu \mathrm{m}$-thick SD rat intestinal section. The changes in color contour may show the content and distribution of lipid, protein, and phosphate/glycoprotein constituents in tissues [24]. Recently, new instruments by using a CCD array will make area mapping much less time consuming. The high performance of CCD focal-plane array (FPA) detector has further enabled the simultaneous collection of several thousand IR spectra to form images within a few minutes $[25,26]$.

\section{Biochemical fingerprints of FT-IR or Raman (micro)spectroscopy}

Undoubtedly, a better diagnostic result obtained from FT-IR spectroscopy strongly depends on the quality of the IR spectra determined. According to the standard operation of IR determination, the sample will absorb the IR radiation and exhibits different vibrations such as stretching, bending, deformation 


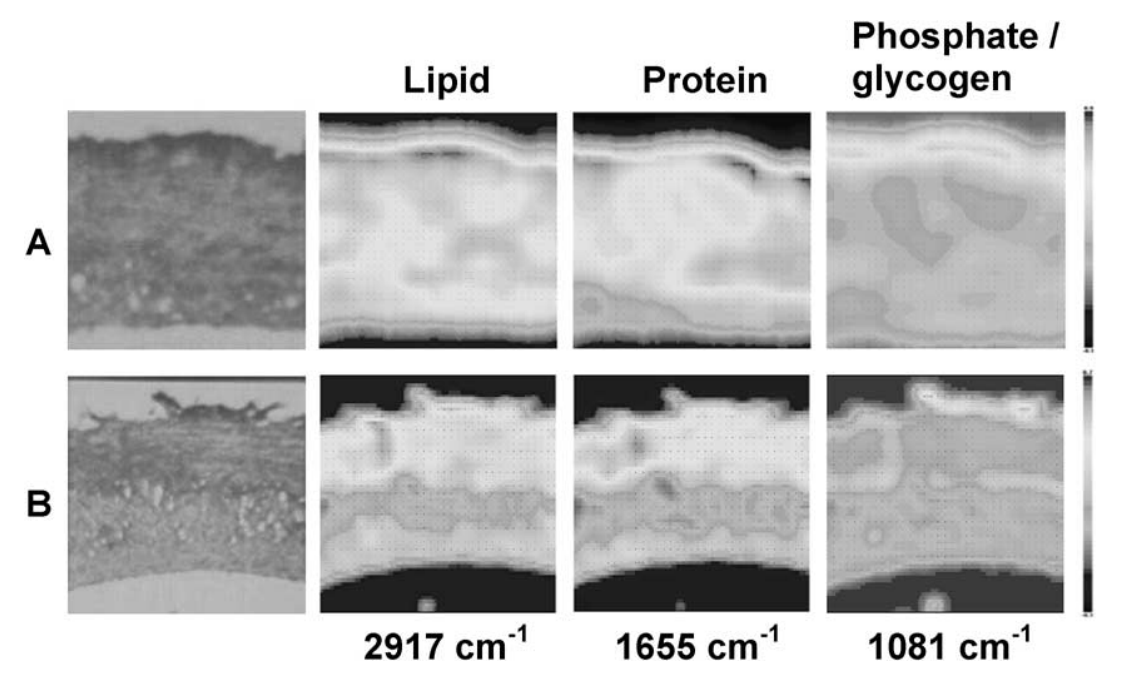

Fig. 3. The application of microscopic FT-IR imaging to the intestinal section of SD rats after feeding cholesterol (A) or cholesterol and the Ginkgo biloba L. extracts (B).

or their combined vibrations. These vibrations are just directly correlated to the molecular structure of biosamples. For most studies of spectral biodiagnosis of biosamples, the mid-IR range of spectrum within $4000-600 \mathrm{~cm}^{-1}$ seems to be more optimal than the near-IR range $\left(14000-4000 \mathrm{~cm}^{-1}\right)$ due to an existence of overtone. In the spectral region of $4000-1500 \mathrm{~cm}^{-1}$ several specific bonds are characterized by various stretching modes of functional groups of molecules. Peaks below $1500 \mathrm{~cm}^{-1}$ are significant assignments for deformation, bending and ring vibrations, and are commonly referred as the fingerprint region of the spectrum. Both microspectroscopies are well known as attractive analytical technique, and their applications to the biological and biomedical fields have rapidly increased. The major reason is that many biomolecules, such as proteins, lipids, nucleic acids, and carbohydrates have characteristic and specific vibrational fingerprints $[6-8,10]$. Several predominant IR bands in biosamples are amide I (1600-1700 $\mathrm{cm}^{-1}: 80 \% \mathrm{C}=\mathrm{O}$ stretching mode), amide II $\left(1500-1600 \mathrm{~cm}^{-1}: 60 \% \mathrm{~N}-\mathrm{H}\right.$ bending and $40 \% \mathrm{C}-\mathrm{N}$ stretching modes), amide III (1200-1330 $\mathrm{cm}^{-1}$ : $40 \% \mathrm{C}-\mathrm{N}$ stretching and $30 \% \mathrm{~N}-\mathrm{H}$ bending modes), asymmetric or symmetric phosphate (near 1225 or $1080 \mathrm{~cm}^{-1}$ ), and glycogen (near $1030 \mathrm{~cm}^{-1}$ ), respectively. Subtle changes in peak shape, peak position, peak intensity and/or area of IR absorbance bands represent different structural conformations of biomolecules. The ratio of IR peak intensity or peak area, $1030 \mathrm{~cm}^{-1} / 1080 \mathrm{~cm}^{-1}$ (glycogen/phosphate ratio) or $1121 \mathrm{~cm}^{-1} / 1020 \mathrm{~cm}^{-1}$ (RNA/DNA ratio), may be used as a potential biomarker to predict the cell proliferation in the normal or malignant tissue $[27,28]$. In addition, the mineralization occurred in the tissues may also be monitored by the ratio of 900-1200 $\mathrm{cm}^{-1}\left(\nu_{1}, \nu_{3}\right.$ phosphate stretching mode) and amide I contours (mineral : matrix ratio), or the ratio of $850-900 \mathrm{~cm}^{-1}$ (total carbonate)/900-1200 $\mathrm{cm}^{-1}\left(\nu_{1}, \nu_{3}\right.$ phosphate) [29]. Moreover, the mineral crystallinity or maturity may also be deduced from the IR peak intensity ratio of $1020 \mathrm{~cm}^{-1}$ (nonstoichiometric apatite) $/ 1030 \mathrm{~cm}^{-1}$ (stoichiometric apatite) [29,30].

Raman spectroscopy also provides similar information concerning the composition and chemical structure to that of FT-IR spectroscopy. Unlike FT-IR determination, Raman measurement can directly detect the hydrated tissue samples since the Raman scattering signal of water molecule is very weak but the fluorescence induced by laser should be avoided [31]. Due to the vibrational activity is different between Raman and FT-IR spectroscopies, some modes in both spectroscopies are active, but others are 
only Raman or FT-IR active. Thus FT-IR and Raman spectroscopies provide similar and complementary detailed information of molecular vibrations [1-5]. Although Raman spectroscopy is a complementary method to the FT-IR spectroscopy, it is particularly optimal to nondestructively analyze the dark and opaque samples, corrosion products and minerals, due to its emission technique [32]. For example, the carbonate and phosphate vibrational modes of biominerals in different biological tissues are easily determined by Raman spectroscopy. The characteristic and comparative absorbance bands found in biological samples are shown in Table 1 for both FT-IR and Raman spectroscopies [1-5,33]. Recently, the development of a confocal Raman microscopy is becoming a potential tool to control the depth of field, eliminate the image degrading out-of-focus information, and collect serial optical sections from thick specimens [35]. This confocal microscopy offers several advantages over conventional optical microscopy, resulting in possible application to the measurement of minute sample and cellular components in single cells $[36,37]$.

\section{Advantages/disadvantages of FT-IR and Raman (micro)spectroscopy}

Although the Raman scattering spectrum provides the same type of information as the IR absorption spectrum, both vibrational techniques have characteristic advantages and disadvantages in biomedical applications due to their different mechanism and selection rules. The advantage of FT-IR microspectroscopy over conventional FT-IR spectroscopy is that it is not only fast, non-destructive, higher signal/noise ratio, higher spatial resolution but also multiple accessories can be used, particularly in the pathological applications [38]. Furthermore, the secondary structure of the proteins may be noninvasively measured in native environment. Although Raman microspectroscopy has less sensitive Raman signal and may also be interfered by laser-induced fluorescence, it has a confocal property, less water interference, and higher spatial resolution. The characteristic advantages and disadvantages of both vibrational microspectroscopies used in different scientific fields are listed in Table $2[5,6,31,33]$.

However, two technical problems should be paid more attention by using both spectroscopic techniques in the practical study of biological tissues. The first problem is water having a very intense IRabsorbing bending mode near $1640 \mathrm{~cm}^{-1}$, which just directly overlapped to the IR absorbance of protein. Fortunately, modern FT-IR instruments and software may overcome this problem to a great extent. The secondary structure of protein in aqueous system can be overcome by a FT-IR spectroscopy with an attenuated total reflection (ATR) measurement $[1-3,7,9]$. On the other hand, there is only a feeble interference of water in the Raman determination. Another problem for Raman determination is the heating destruction to the sample after long-term laser irradiation [39]. In order to obtain an enhanced Raman spectrum of sample, the prolonged exposure of a specimen to a laser beam is necessary. However, the heat generated by the laser may alter or destroy the biosample texture in the long-term exposure of measurement. To overcome the heating destruction of sample, the shorter irradiation time with a repeated scanning number seems to be optimal.

\section{Current biological applications of vibrational microspectroscopy}

Until now, both FT-IR and Raman vibrational microspectroscopies have been extensively applied to the diverse biological researches, such as the molecular compound distribution (lipids, proteins, nucleic acids, carbohydrate) and chemical information to histological structure of a single cell in cell biology 
Table 1

Infrared and Raman characteristic functional frequencies of biological samples [1-5,33]

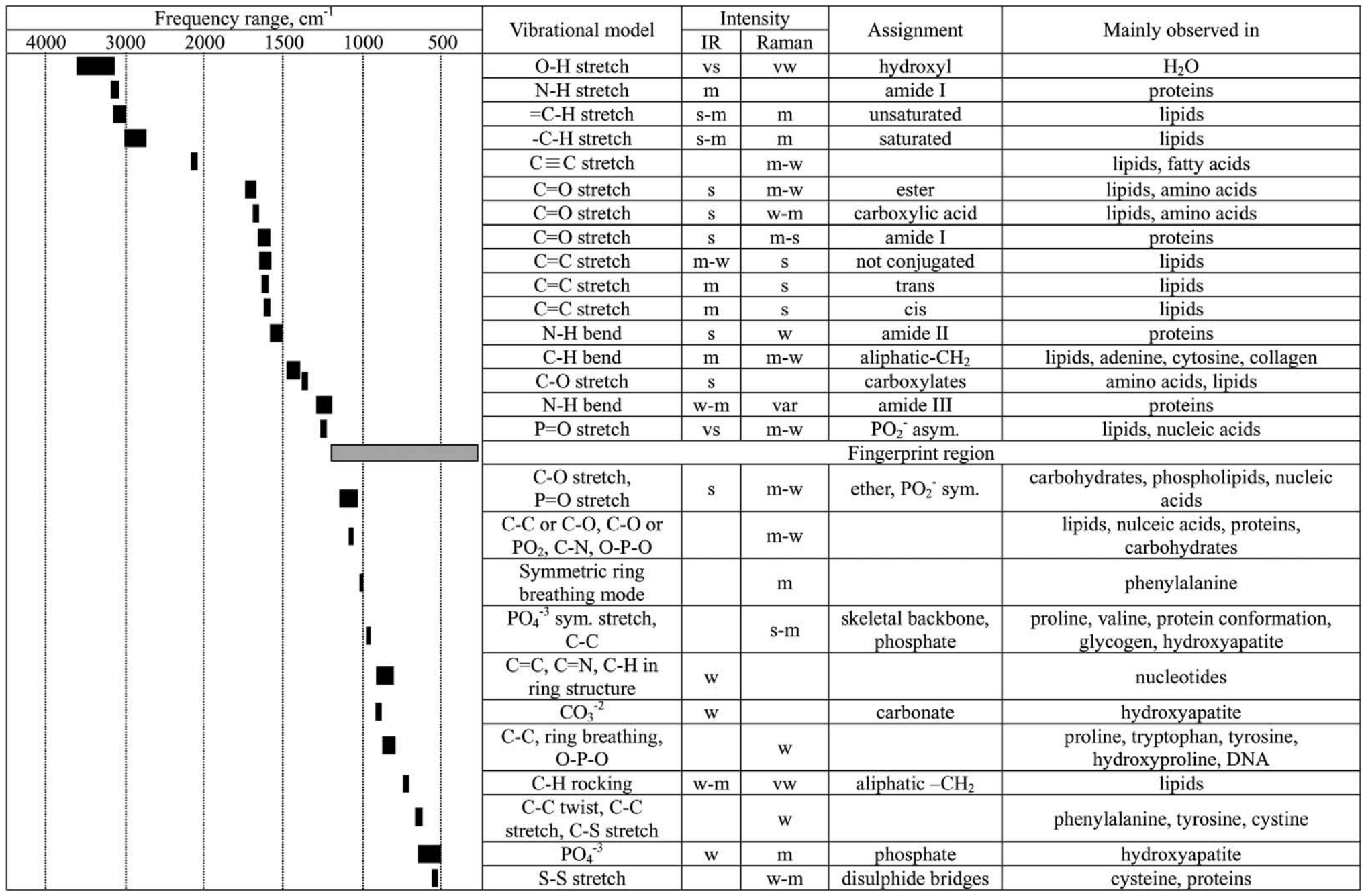

s: strong; m: medium; vs: very strong; w: weak; vw: very weak. 
Table 2

The characteristic advantages and disadvantages of FT-IR and Raman microspectroscopies used in the biological applications $[5,6,31,32]$

\begin{tabular}{lll}
\hline & FT-IR & Raman \\
\hline Phenomenon & Absorption & Scattering \\
Sample preparation & Required & None \\
Accessories & Multiple & Single \\
Data collection & Fast & Slow \\
Glass interference & Strong & None \\
Sensitivity & Good & Fair \\
Water interference & Strong & Very weak \\
Spatial resolution & $\geqslant 10 \mu \mathrm{m}^{2}$ & $\geqslant 1 \mu \mathrm{m}^{2}$ \\
Signal-to-noise & High & Low \\
Fluorescence & None & Overwhelming \\
Heat destruction & None & Strong \\
Confocality & No & Yes \\
Mapping/imaging & Yes & Yes \\
\hline
\end{tabular}

study [10-14], rapid and accurate identification of the nature of colony development and biofilm formation for microorganisms and microbial fermentations [40,41], the chemical and functional characteristics of plant tissues and seeds [42,43], the interaction of implants with biological system [31,44,45], and the detection of drug abuse and drug distribution in a forensic study [46,47]. Tables 3 and 4 list many examples and applications of different human tissues determined by using FT-IR and/or Raman spectroscopy combined with/without microscopy [48-120].

\section{Spectral biodiagnoses of diseased human tissues in our laboratory}

Since both vibrational microspectroscopic detections can qualitatively and quantitatively distinguish the differences from the spectral characteristics of many molecules, thus the molecular and submolecular spectral profiles may be used to define and differentiate the diseased and healthy human tissues. Here, we will review several biomedical diagnoses of disordered human tissues investigated by using FT-IR and/or Raman microspectroscopy in our laboratory. All the studies were approved by the Institutional Review Board of our hospital and all procedures adhered to the Declaration of Helsinki. The schematic diagram of different disordered organs in the human body diagnosed in our laboratory is shown in Fig. 4.

\subsection{Diagnosis of human ophthalmic disorders}

\subsubsection{Cataractous lens capsule [120-125]}

The lens capsule mainly constructed by type IV collagen is an acellular basement membrane of eye to maintain the shape of the lens. It also protects the interior of the lens from ultraviolet radiation. Although the morphology, physico-chemical properties, functional and conformational structure of type IV collagen have been reported to be easily influenced by many events such as ages, diseases or other foreign stress factors, little attention has been paid to clarify the role of human lens capsule in cataract formation. Our groups had first used a FT-IR microspectroscopy with second-derivative analysis and curve-fitting program to differentiate the grading and maturity of cataracts based on the progressive changes in protein 
Table 3

Examples for detection and identification of human tissues by FT-IR microspectroscopy

\begin{tabular}{|c|c|c|}
\hline Human tissues & Methods & References \\
\hline Normal and aneurismal ascending aortic tissues & Micro FT-IR & {$[48]$} \\
\hline Iliac crest & Micro FT-IR & [49] \\
\hline Acute human infections & Micro FT-IR & {$[50]$} \\
\hline Colorectal adenocarcinoma & Micro FT-IR & [51] \\
\hline Lymphoid tumors & Micro FT-IR & [52] \\
\hline Acute lymphoblastic leukemia & Micro FT-IR & [53] \\
\hline Osteonal bone & Micro FT-IR & [54] \\
\hline Periodontal tissue & Micro FT-IR & [37] \\
\hline Pancreatic cancer & Micro FT-IR & [55] \\
\hline Normal and malignant colonic tissues & Micro FT-IR & [57] \\
\hline Colon cancer tissue & Micro FT-IR & [58] \\
\hline Lung cancerous and noncancerous tissues & Micro FT-IR & [59] \\
\hline Gastric tissues & Micro FT-IR & [60] \\
\hline Photoreceptor outer segments of the retina & Micro FT-IR & [61] \\
\hline Brain tissues & Micro FT-IR & [62] \\
\hline Arterial tissue & Micro FT-IR & [63] \\
\hline Breast cancer tissue & Micro FT-IR & {$[64]$} \\
\hline Melanoma and colon carcinoma tissues & Micro FT-IR & [65] \\
\hline Alzheimer's diseased brain tissue & Micro FT-IR & [66] \\
\hline Lung carcinomas & Micro FT-IR & [67] \\
\hline Dental tissues & Micro FT-IR & [68] \\
\hline Atherosclerotic human artery & Micro FT-IR & [69] \\
\hline Brain metastases & Micro FT-IR & [70] \\
\hline Bone tissue & Micro FT-IR & [71] \\
\hline Cervical precancerous tissue & Micro FT-IR & [72] \\
\hline Cervical smears & Micro FT-IR & [73] \\
\hline Colon cancer & Micro FT-IR & [74] \\
\hline Colon carcinoma & Micro FT-IR & [75] \\
\hline Mineral content and crystallinity in bone & Micro FT-IR & [76] \\
\hline Cirrhotic liver tissue & Micro FT-IR & [77] \\
\hline Brain metabolism & Micro FT-IR & [78] \\
\hline Spleen & Micro FT-IR & [79] \\
\hline Cancerous brain tissue (astrocytoma, glioblastoma) & Micro FT-IR & {$[80]$} \\
\hline Dental calculus & Micro FT-IR & [81] \\
\hline Brain tissue, brain tumors and tumor cells & Micro FT-IR & [82] \\
\hline Squamous cell cervical carcinoma & Micro FT-IR & [83] \\
\hline Ovarian tissues & $\begin{array}{l}\text { Micro FT-IR/ } \\
\text { Micro Raman }\end{array}$ & [84] \\
\hline Prostate cancer & Micro FT-IR & {$[85,86]$} \\
\hline Skin nevus and melanoma & Micro FT-IR & [87] \\
\hline Skin malignant melanoma & Micro FT-IR & [88] \\
\hline Cervical cancer and melanoma & Micro FT-IR & [89] \\
\hline Inflammatory bowel diseases & Micro FT-IR & [90] \\
\hline
\end{tabular}


Table 4

Examples for detection and identification of human tissues by Raman spectroscopy

\begin{tabular}{|c|c|c|c|}
\hline Human tissues & Methods & Laser excitation & References \\
\hline Skin & Confocal Raman & $720 \mathrm{~nm} / 850 \mathrm{~nm}$ & {$[91]$} \\
\hline Eye lens & Confocal Raman & $676 \mathrm{~nm}$ & {$[92]$} \\
\hline Normal, benign and malignant breast tissues & Raman & $785 \mathrm{~nm}$ & [93] \\
\hline Cornea & Confocal micro Raman & $632.8 \mathrm{~nm}$ & [94] \\
\hline Oral carcinoma & FT-Raman & $1064 \mathrm{~nm}$ & [95] \\
\hline Colorectal tissue & FT-Raman & $1064 \mathrm{~nm}$ & [96] \\
\hline Parathyroid tissue & Near-IR micro Raman & $830 \mathrm{~nm}$ & [97] \\
\hline Laryngeal cancer & Micro Raman & $830 \mathrm{~nm}$ & [98] \\
\hline Prostatic adenocarcinoma & Micro Raman & $832 \mathrm{~nm}$ & [99] \\
\hline Bone tissue & Micro Raman & $633 \mathrm{~nm}$ & [100] \\
\hline Coronary atherosclerosis & Raman/Confocal micro Raman & $830 \mathrm{~nm}$ & [101] \\
\hline Carcinogenesis of oesophagus & Micro Raman/mapping & $830 \mathrm{~nm}$ & {$[102]$} \\
\hline Breast tissue & Raman/optical fiber & $830 \mathrm{~nm}$ & [103] \\
\hline Corneocyte maturation & Confocal micro Raman & $830 \mathrm{~nm}$ & [104] \\
\hline \multirow{2}{*}{$\begin{array}{l}\text { Meningioma } \\
\text { Normal, inflammatory, premalignant, } \\
\text { malignant oral tissues }\end{array}$} & Near IR micro Raman & $847 \mathrm{~nm}$ & {$[105]$} \\
\hline & Raman & $785 \mathrm{~nm}$ & [106] \\
\hline Atherosclerosis in human carotid artery & FT-Raman & $1064 \mathrm{~nm}$ & [107] \\
\hline Oral carcinoma & FT-Raman & $1064 \mathrm{~nm}$ & [108] \\
\hline Laryngeal specimens & Raman & $785 \mathrm{~nm}$ & [109] \\
\hline Ovarian tissues & Micro-Raman & $832.2 \mathrm{~nm}$ & {$[110]$} \\
\hline Native brain tissue and intracranial tumors & Raman mapping & $785 \mathrm{~nm}$ & [111] \\
\hline Bladder and prostate cancer & Near-IR Raman & $785 \mathrm{~nm}$ & [112] \\
\hline Pterygium tissue & Confocal micro Raman & $830 \mathrm{~nm}$ & [113] \\
\hline Brain lipids & Micro Raman & $785 \mathrm{~nm}$ & [114] \\
\hline Lymph nodes & Micro-Raman/micro FT-IR & $632 \mathrm{~nm}$ & [115] \\
\hline Basal cell carcinoma & Confocal micro Raman & $514.5 \mathrm{~nm}$ & [116] \\
\hline Lung cancer & Near-IR Raman & $785 \mathrm{~nm}$ & [117] \\
\hline Oral lesions & Micro Raman & $847 \mathrm{~nm}$ & [118] \\
\hline Epithelial pre-cancers and cancers & Near-IR/micro Raman & $830 \mathrm{~nm}$ & [119] \\
\hline Corneal hydration & Confocal micro Raman & $632.8 \mathrm{~nm}$ & {$[120]$} \\
\hline
\end{tabular}

secondary conformation of cataractous human lens capsules (Fig. 5). Moreover, the effect of risk factors (diabetes, glaucoma, systemic hypertension, myopia or heredity) of cataract formation on the protein secondary structures and its compositions of cataractous lens capsules in patients have been investigated. Our studies found that the duration of diabetes was a major influencing factor to alter the protein secondary conformation of the cataractous lens capsules in diabetic patients not only by decreasing the triple helix content but also by markedly increasing the random coil structure. The compositions of both random coil and $\beta$-structure ( $\beta$-sheet and $\beta$-turn) in cataractous human lens capsules were increasingly induced by systemic hypertension, myopia or glaucoma, but $\alpha$-helix content clearly decreased. A possible pathway of cataract formation exacerbated by systemic hypertension or glaucoma was proposed. According to the results, we proposed that the risk factors might change the protein conformational structure of lens capsule, then cause the alteration of membrane transport and permeability for ions, and finally increase the intraocular pressure to exacerbate cataract formation (Fig. 6). The content of aspartic acid had also been reduced significantly in the lens capsules of hereditary cataractous patients. 


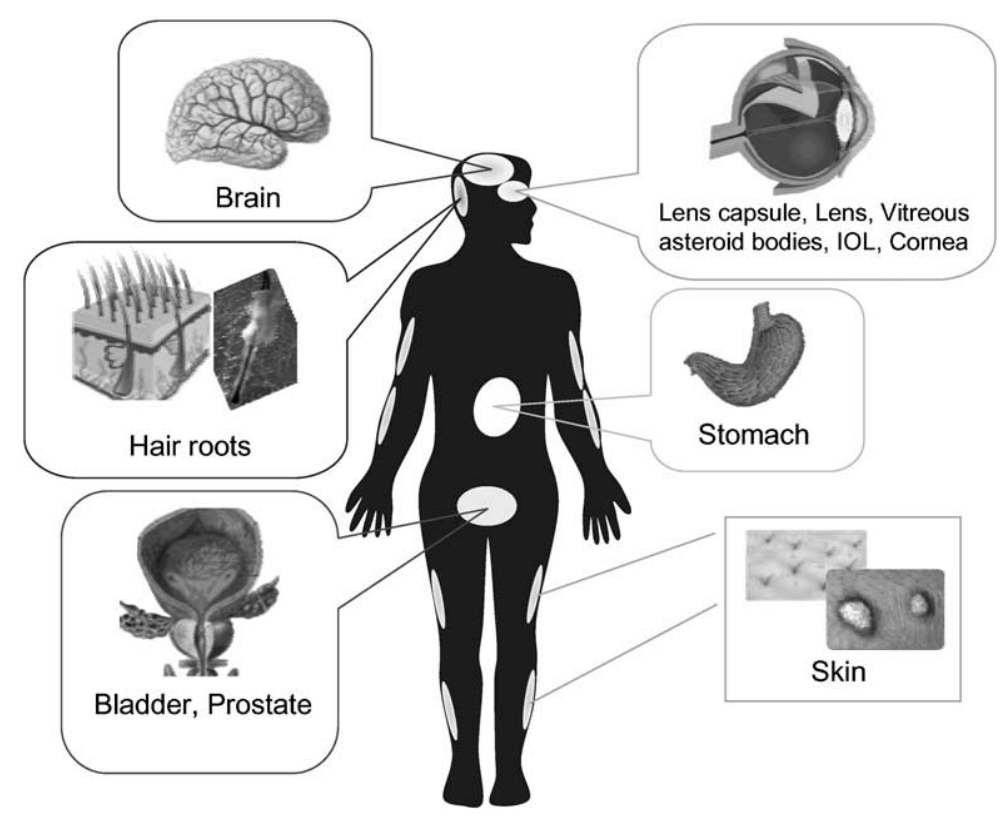

Fig. 4. The schematic diagram of different disordered organs in the human body diagnosed in our laboratory.

(A) Normal lens capsule

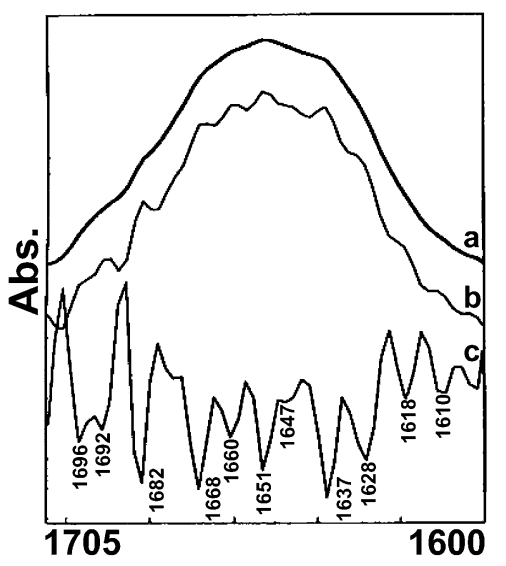

(B) Immature lens capsule

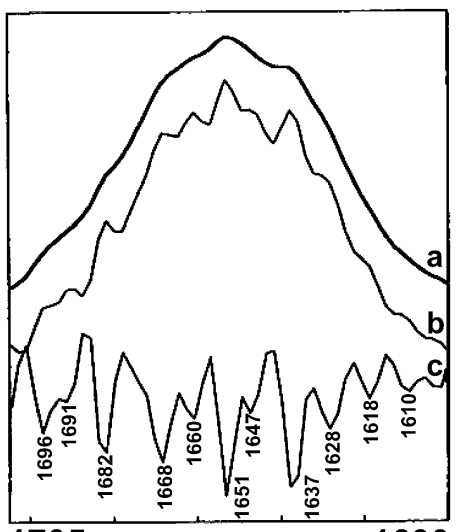

16001705
(C) Mature lens capsule

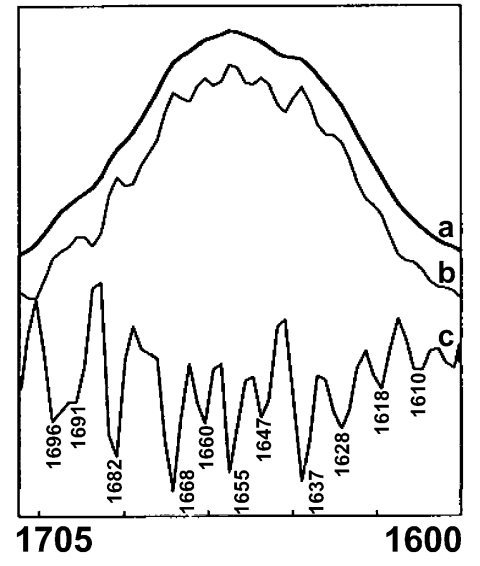

Wavenumber $\left(\mathrm{cm}^{-1}\right)$

Fig. 5. The original (a), deconvoluted (b) and second-derivative (c) IR spectra of amide I band for three types of lens capsules [120].

Our conclusion suggested that the cataract formation might be possibly associated with the age-related alteration of protein secondary structure in the lens capsule and exacerbated by several diseases-related risk factors.

\subsubsection{Cataractous lens [126]}

Two normal lenses, 10 immature cataractous lenses without any complication and 4 immature cataractous lenses with glaucoma were used after surgical operation for investigating the changes in the hu- 


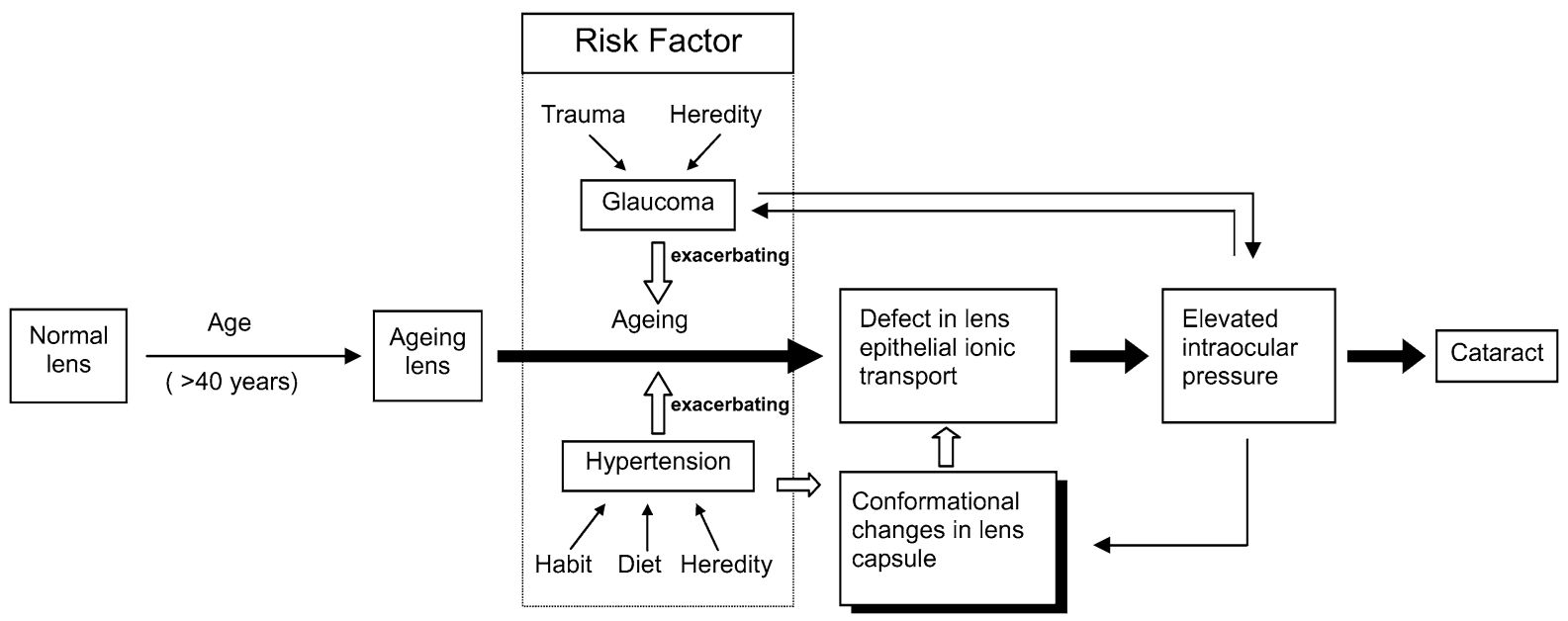

Fig. 6. Speculative scheme for exacerbating cataract formation by systemic hypertension or glaucoma [124].

man lens lipid and protein structures. The ATR/FT-IR results indicated that the compositional ratio of $2965 / 2930 \mathrm{~cm}^{-1}$, due to the methyl groups of proteins and methylene groups of phospholipids, for normal lens was about 0.702 , but the ratio for cataractous lenses without glaucoma was 0.382 and for glaucomatous lenses was 0.377 . The maximum IR peak position in amide I band of normal lens, immature cataractous lenses without complications or with glaucoma was respectively found at 1632, 1630 or $1622 \mathrm{~cm}^{-1}$, suggesting that the $\beta$-sheet structure was a predominate component in it. The peak intensity ratio of amide I/amide II $\left(1632 \mathrm{~cm}^{-1} / 1545 \mathrm{~cm}^{-1}\right)$ for normal lenses was in the range of $2.20-2.33$, whereas this ratio for immature cataractous lenses without glaucoma $\left(1630 \mathrm{~cm}^{-1} / 1545 \mathrm{~cm}^{-1}\right)$ was $1.28-1.41$ but was $1.04-1.13$ for glaucomatous lens $\left(1622 \mathrm{~cm}^{-1} / 1545 \mathrm{~cm}^{-1}\right)$. The decreased amount of $\alpha$-helix and random coil structures but the enhanced content of $\beta$-sheet structure in the immature cataractous human lens induced by glaucoma might be due to an intermolecular hydrogen-bonded formation in lenses. The results revealed that the alternations in lens lipid and protein structures played an important role to induce cataract formation. The glaucomatous lens was more pronounced.

\subsubsection{Senile cataractous lens calcification [127]}

The chemical composition of a small calcified plaque on the surface of a senile cataractous lens isolated from a male patient was determined by using FT-IR and confocal Raman microspectroscopies. The noncalcified area of the same lens and hydroxyapatite (HA) were selected as a control. Several unique IR absorption bands at 960,1034 and $1090 \mathrm{~cm}^{-1}$ assigned to the $\nu_{1}$ and $\nu_{3}$ phosphate stretching modes and at $875 \mathrm{~cm}^{-1}$ attributed to carbonate band were clearly displayed in the IR spectra of calcified plaque. A peak at $961 \mathrm{~cm}^{-1}$ due to the $\nu_{1}$ phosphate stretching mode was also evidenced in the Raman spectra of calcified plaque and was near to $958 \mathrm{~cm}^{-1}$ for HA (Fig. 7). In fully mature minerals, the carbonate ions may occupy two anionic sites of the apatite structure or may be in surface site locations [128]. The $\mathrm{CO}_{3}^{2-}$ ions occupying the $\mathrm{OH}^{-}$sites are generally defined as type-A carbonate apatites, but the $\mathrm{CO}_{3}^{2-}$ ions occupying the $\mathrm{PO}_{4}^{3-}$ sites are defined as type-B carbonate apatites. The IR spectra of minerals exhibited three components of these carbonate bands in the spectral region of $860-890 \mathrm{~cm}^{-1}$ : type-A carbonate $\left(>878 \mathrm{~cm}^{-1}\right)$, type-B carbonate $\left(>871 \mathrm{~cm}^{-1}\right)$ and an unstable carbonate location (near $\left.866 \mathrm{~cm}^{-1}\right)$, respectively. In this study, the calcified plaque formed within the cataractous lens was found to mainly consist of a mature HA, in which the content of type-A carbonate apatites (11.4\%), type-B carbonate 
(A) FT-IR spectra

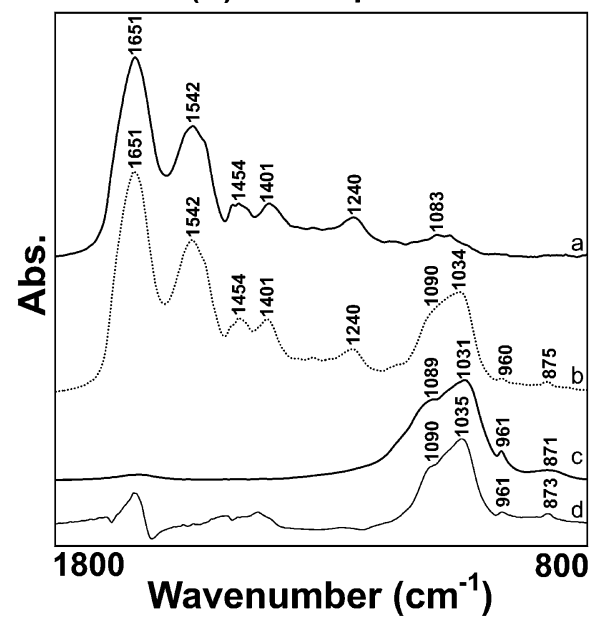

(B) Raman spectra

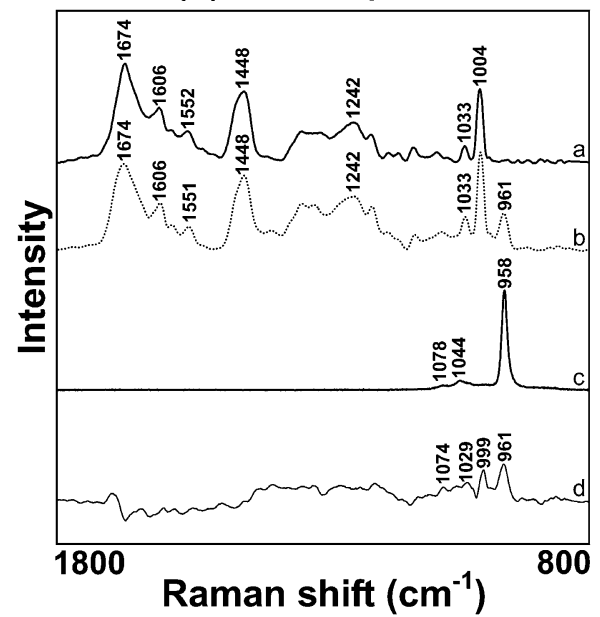

Fig. 7. FT-IR (A) and Raman (B) spectra for different lens samples [127]. Key: a, non-calcified lens area; b, calcified plaque; c, HA reference sample; d, difference spectrum between (a) and (b).

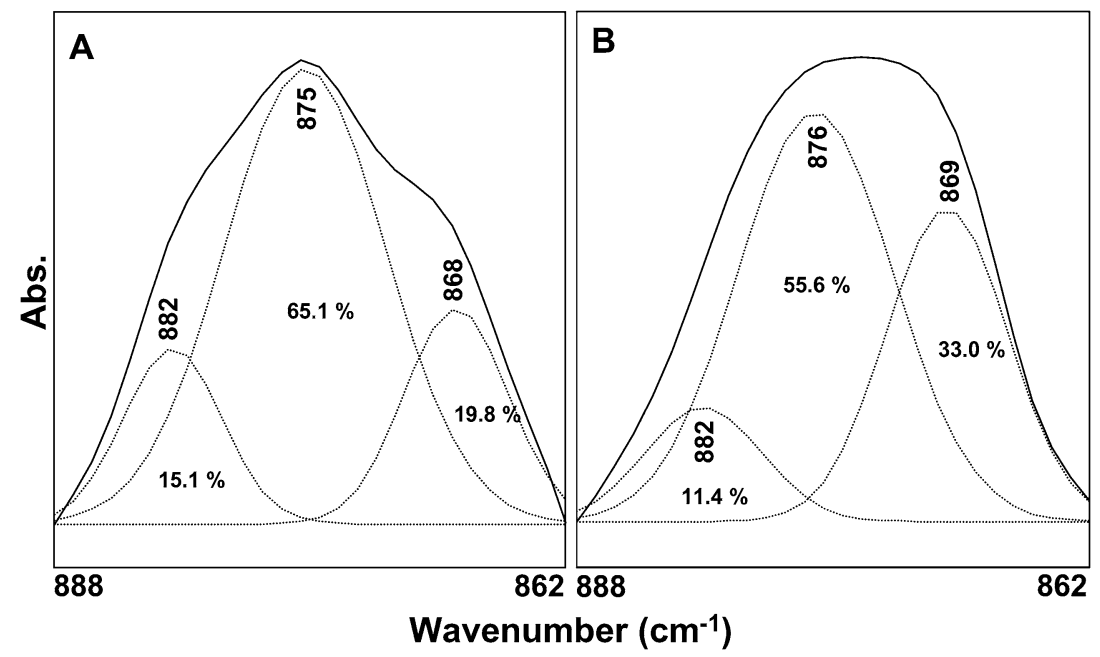

Fig. 8. The assignment and composition of the curve-fitted original FT-IR spectrum of HA reference sample (A) and the difference spectrum between non-calcified area and calcified plaque (B) [127].

apatites (55.6\%) and liable surface carbonate ions (33.0\%) were close to the result of HA sample after applying with curve-fitting program (Fig. 8). A higher content of the liable carbonate implied that the calcification in this calcified lens was incomplete and still in progress.

\subsubsection{Opacification of intraocular lens [129]}

FT-IR microspectroscopy combining with ATR microsampling technique and micro-Raman confocal spectrophotometer were used to detect the component of opaque deposited materials on the surface of explanted acrylic hydrogel intraocular lens (IOL). The brand-new IOL exhibited a very smooth, transparent and featureless surface by observing with a confocal laser scanning microscope, but the explanted 
(A) HA

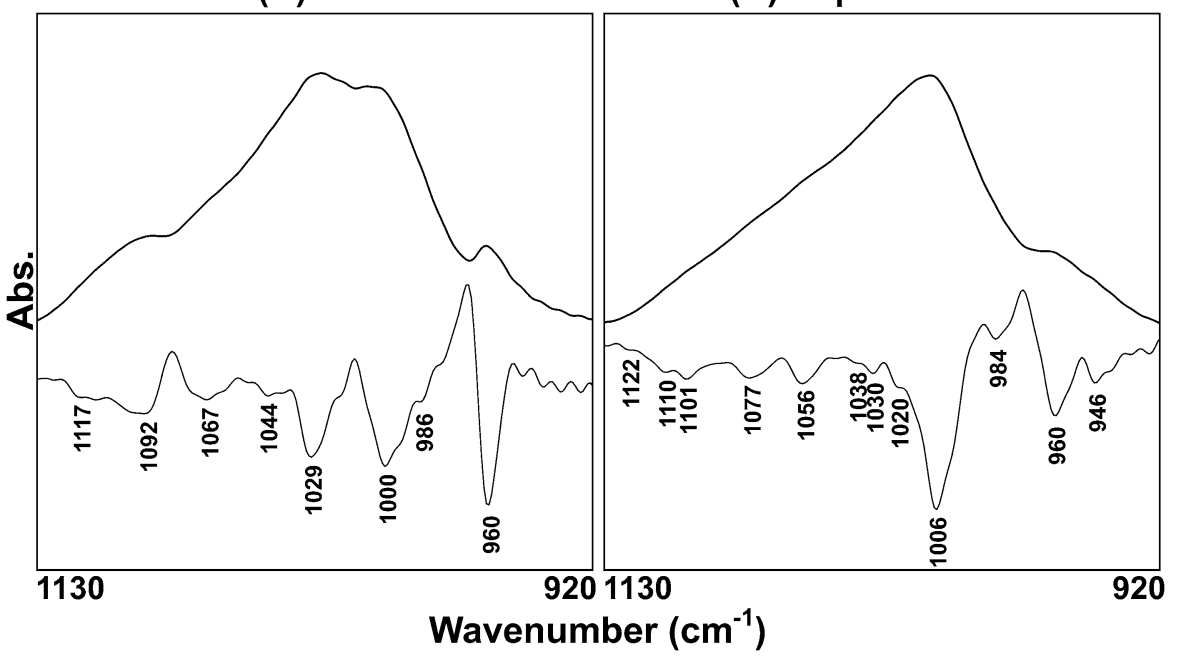

Fig. 9. The second-derivative ATR/FT-IR spectra of HA sample (A) and explanted IOL (B) [129].

IOL had an irregular cerebriform-like opaque appearance. Both ATR/FT-IR and Raman microspectroscopic analyses showed that the deposit on the surface of explanted IOL was consisted of octacalcium phosphate and type-B carbonate apatites, leading to the opalescence of IOL. It has been reported that the early stages of immature poorly crystalline HA having peaks at 960, 985, 1020, 1038, 1055, and $1075 \mathrm{~cm}^{-1}$ might shift to the mature HA with peaks at 960, 982, 999, 1030, 1055, 1075, 1096, and $1116 \mathrm{~cm}^{-1}$. The former belonged to the nonstoichiometric apatites, whereas the latter was stoichiometric apatites. In the present study, the second-derivative IR spectra of HA (A) and explanted IOL (B) also exhibited similar peaks to the above positions, as shown in Fig. 9. Obviously, the HA sample used in this study was close to the stoichiometric and mature crystalline HA. However, the calcified deposits on the explanted IOL was similar to the freshly precipitated, immature poorly crystalline HA. Both vibrational microspectroscopic examinations also confirmed the mineralization still in progress on the surface of IOL even ocular implantation for 2 years.

\subsubsection{Identification of oily-like material on IOL [130]}

A small oily-like hump on the tempo-upper quadrant of anterior surface of IOL was found under a slit-lamp microscope for an old man after IOL implantation. The surgeon failed to remove the hump with Nd:YAG laser. One year after implantation, his vision decreased to 20/400 because this oily-like hump extended to the central part of IOL surface. The oily-like material deposited on the explanted IOL surface after IOL exchange was examined by FT-IR and confocal Raman microspectroscopies. The IR bands near 2955,2920 , and $2850 \mathrm{~cm}^{-1}$ for oily-like material were assigned to the asymmetric and symmetric $\mathrm{CH}$ stretching modes, the peaks at 1463 and $1377 \mathrm{~cm}^{-1}$ were the result of the $\mathrm{CH}_{2}$ and $\mathrm{CH}_{3}$ bending vibrations. The FT-IR spectrum of oily-like material were just the same as that of the fatty acyl chains of ointment base for garamycin ophthalmic ointment. This implied that the oily-like material should be the oily base of ointment. Raman bands at 2931, 2887, and $2856 \mathrm{~cm}^{-1}$ (asymmetric and symmetric $\mathrm{CH}$ stretching modes) and at 1444 and $1303 \mathrm{~cm}^{-1}\left(\mathrm{CH}_{2}\right.$ and $\mathrm{CH}_{3}$ bending vibrations) also confirmed the results of FT-IR spectrum. This result identified a long-term retained garamycin ophthalmic ointment on an IOL after sutureless cataract surgery. 


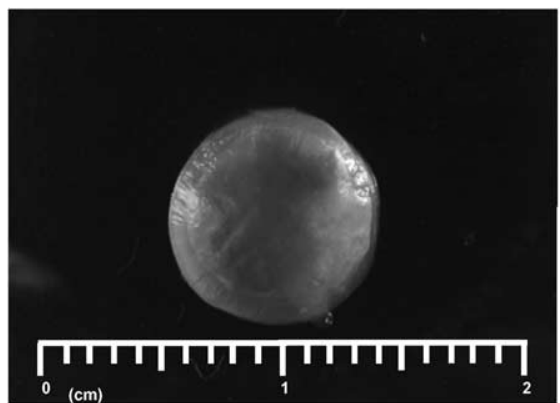

(A) FT-IR spectra

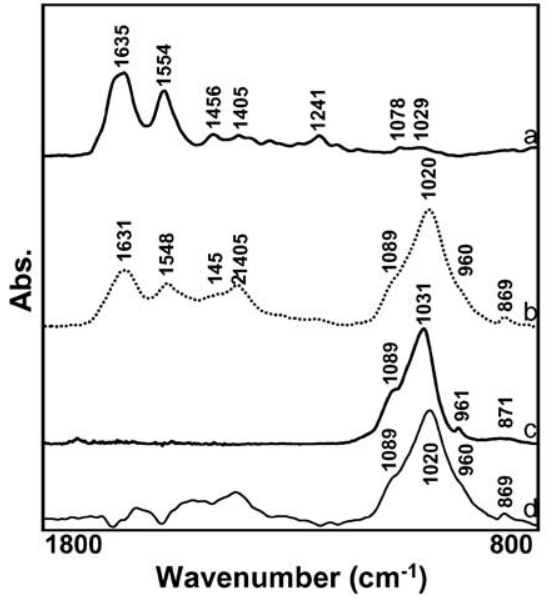

(B) Raman spectra

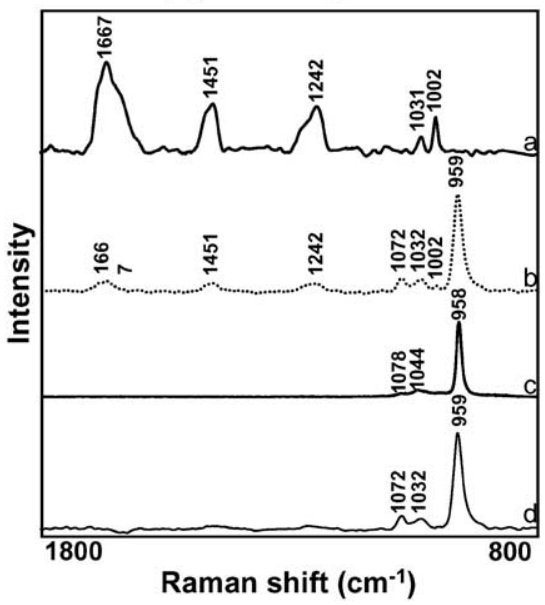

Fig. 10. FT-IR (A) and Raman (B) spectra for different corneal samples [131]. Key: a, non-calcified corneal area; b, calcified corneal area; c, HA reference sample; d, difference spectrum between (a) and (b).

\subsubsection{Corneal calcification [131]}

The chemical composition of the excised corneal calcified opaque deposit on the surface of an excised cornea from a male patient was also quickly and quantitatively investigated by microscopic ATR/FT-IR and confocal Raman spectroscopies.

Microscopic observation indicated that a white-grayish opaque plaque-like deposit was seen (Fig. 10). A peak at $1020 \mathrm{~cm}^{-1}$ assigned to the stretching vibration of phosphate of the immature poorly crystalline and nonstoichiometric HA was observed from the IR spectrum of corneal calcified deposit, as compared with the peak at $1031 \mathrm{~cm}^{-1}$ due to the mature, crystalline and stoichiometric HA [132]. In addition, higher contents of two IR spectral peaks at $871 \mathrm{~cm}^{-1}$ (type-B carbonate apatite) and at $866 \mathrm{~cm}^{-1}$ (a labile carbonate) after curve-fitting were also evidenced in the corneal calcified deposit. The dominate peak at $959 \mathrm{~cm}^{-1}$ due to its stretching mode of phosphate was also found in the Raman spectrum of corneal calcified deposit. The results indicated that the corneal calcified deposit was consisted of an immature poorly crystalline HA with higher content of the type-B carbonate apatite within the corneal collagen matrix.

\subsubsection{Unique component in vitreous asteroid bodies [133]}

Asteroid hyalosis $(\mathrm{AH})$ is a degenerative disease of the vitreous that consists of multiple discrete yellowish-white minute spherical particles, termed asteroid bodies (ABs), suspended within the vitreous humor. The origin, composition, and formation of $\mathrm{ABs}$ in the vitreous are still incompletely elu- 


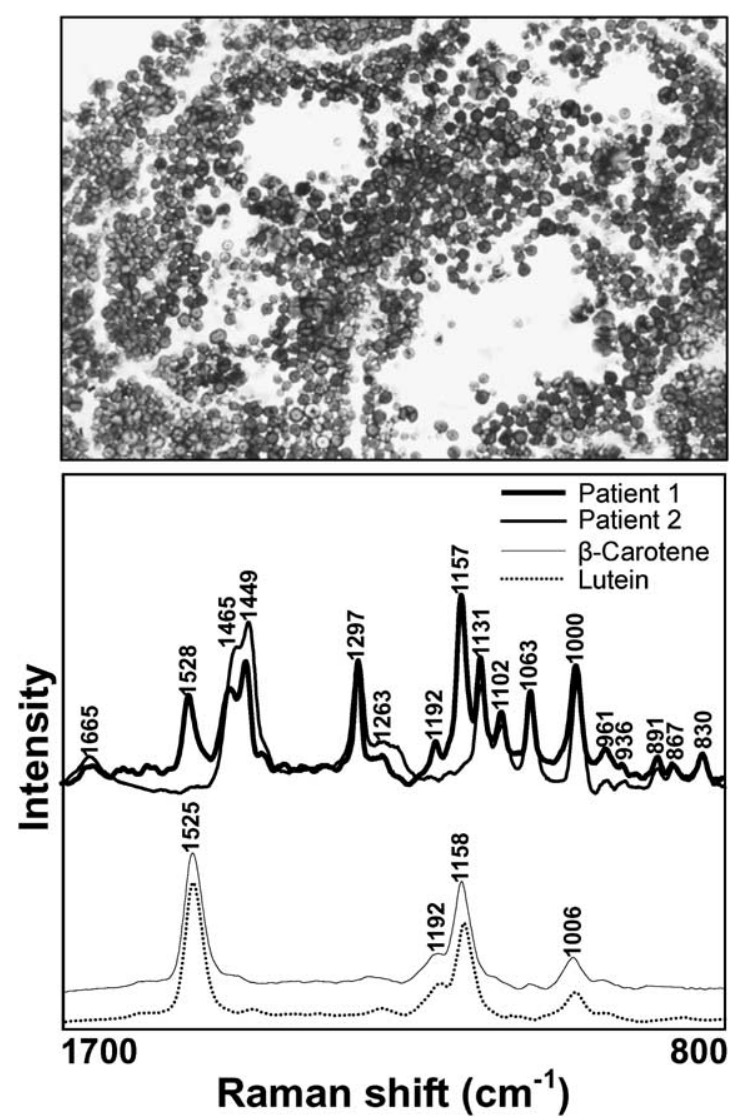

Fig. 11. Representative photograph of one ABs specimen suspended within the vitreous humor and Raman spectra of two ABs specimens from both $\mathrm{AH}$ patients, and $\beta$-carotene as well as lutein [133].

cidated, although several techniques had been attempted to investigate their structure and composition [134-136]. Until now, the structural compositions of ABs had been proposed to consist of calcium hydroxyapatite, sphingomyelin, triglyceride, cholesterol, ceramide dihexoside, cerebroside sulfate, proteoglycans, and glycosaminoglycan in the vitreous humor. In this study, the morphology and components of the minute $\mathrm{AB}$ specimens excised from two AH patients were observed by optical microscopy and determined by using confocal Raman microspectroscopy. The high performance liquid chromatography (HPLC) was also used to verify the component. Figure 11 showed the representative photograph of one $\mathrm{AB}$ specimen suspended within the vitreous humor. A lot of particles entrapped in the vitreous gel were clearly observed in the $\mathrm{AB}$ aggregates. The particle size of $\mathrm{ABs}$ ranged approximately between 20 and $50 \mu \mathrm{m}$. Both $\mathrm{AB}$ specimens displayed similar appearances. Two unique peaks at 1528 and $1157 \mathrm{~cm}^{-1}$ were found in the Raman spectrum of the $\mathrm{AB}$ specimen for patient 1 alone, which were in close agreement with that of the Raman peaks at 1525 and $1158 \mathrm{~cm}^{-1}$ for $\beta$-carotene and/or lutein [137]. However, HPLC analytical data clearly verified that the retention time for the extracted sample from the $\mathrm{AB}$ specimen of patient 1 was observed at $13.68 \mathrm{~min}$ and just identical to that of $\beta$-carotene at 13.75 min rather than lutein at 2.97 min. Furthermore, the lack of any peak in the HPLC profile for the $\mathrm{AB}$ specimen of patient 2 also confirmed the absence of Raman peaks at 1525 and $1158 \mathrm{~cm}^{-1}$. Thus this study strongly suggested that $\beta$-carotene as a unique component of ABs might be specifically de- 
tected from the $\mathrm{AB}$ specimen of one $\mathrm{AH}$ patient by using confocal Raman microspectroscopy and HPLC analysis.

\subsection{Alcohol-induced structural alteration of human gastric mucosa}

Gastric mucous gel that lines the surface of gastric mucosa is crucial for epithelial protection. In order to simulate the effect of ethanol in the alcoholic drinks on the human gastric mucosa, the ATR/FT-IR microspectroscopy was used to investigate the protein secondary structure of human gastric mucosa (isolated from human gastric wall) after treatment with ethanol, in vitro. The effect of concentration and exposure time of ethanol on the structural changes of this gastric mucosa was also studied. The peak intensity and position of IR spectra for gastric mucosa was changed significantly with the increases of ethanol concentration and length of exposure $[138,139]$. The IR peak intensity due to the $\beta$-sheet and/or $\beta$-turn conformation in amide I and II bands of gastric mucosa was clearly increased after treatment with ethanol. Moreover, the peak at $1635 \mathrm{~cm}^{-1}$ shifted to $1630 \mathrm{~cm}^{-1}$ after treatment with $40 \%$ ethanol for $3 \mathrm{~h}$, or $80 \%$ ethanol for $1 \mathrm{~h}$, and a distinct shoulder also appeared at $1643 \mathrm{~cm}^{-1}$. This shift was occurred more rapidly and was more pronounced after exposure of mucosa to $80 \%$ ethanol. Ethanol treatment might also transform the secondary structure of amide III in gastric mucosa from $\alpha$-helix to random coil with extensive unfolding. The absorption between 1180 and $980 \mathrm{~cm}^{-1}$ assigned to glycoprotein structure was also reduced after treatment with ethanol. This strongly revealed that ethanol markedly influenced the conformational structure of proteins and carbohydrates of gastric mucus gel. The dehydration and interference of hydrophobic interactions in the isolated mucus gel after pretreatment with ethanol might be responsible for this conformational change.

\subsection{Diagnosis of skin disorders}

\subsubsection{Skin cancer [140]}

Pilomatrixoma (PMX) is a benign cutaneous epithelial tumor that occurs in the dermis or subcutaneous tissues. PMX may be diagnosed from sebaceous cysts by noninvasive physical imaging examinations, which is only capable of providing morphological information. In this study, confocal Raman microspectroscopy was used to qualitatively identify and distinguish the chemical components of the PXM tissues from that of normal skin tissue. The normal skin dermis, type I collagen and HA were used as control. The excised specimens from two patients were diagnosed as a typical PMX, in which one specimen was a soft mass but the other was a hard mass. The Raman spectrum of normal skin dermis was found to be similar to the Raman spectrum of type I collagen. The major differences of Raman peak intensity between normal skin dermis and soft or hard PMX mass were obvious at 1622, 1558, 1400-1230, 1128, 1000-850, 749 and $509 \mathrm{~cm}^{-1}$ (Fig. 12). In particular, the peak at $1665 \mathrm{~cm}^{-1}$ assigned to amide I band shifted to $1655 \mathrm{~cm}^{-1}$ and the peak at $1246 \mathrm{~cm}^{-1}$ corresponding to amide III band was reduced in its intensity in hard PMX mass. The significant changes in collagen content and its structural conformation, the higher content of tryptophan, and disulfide formation in PMX masses were markedly evidenced. In addition, the shoulder and weak peak at $960 \mathrm{~cm}^{-1}$ assigned to the stretching vibration of $\mathrm{PO}_{4}^{3-}$ of HA also appeared respectively in the Raman spectra of soft and hard PMX masses, suggesting the occurrence of calcification of HA in the PMX tissue, particularly in the hard PMX mass.

\subsubsection{Skin calcification [141]}

The clinical diagnosis of calcinosis cutis has been established by time-consuming histopathological or immunohistochemical evaluation. In this study, a young Chinese lady had undergone surgery for a calcinosis cutis (Fig. 13). The skin lesion was totally excised and cut into two equal parts to send one for 

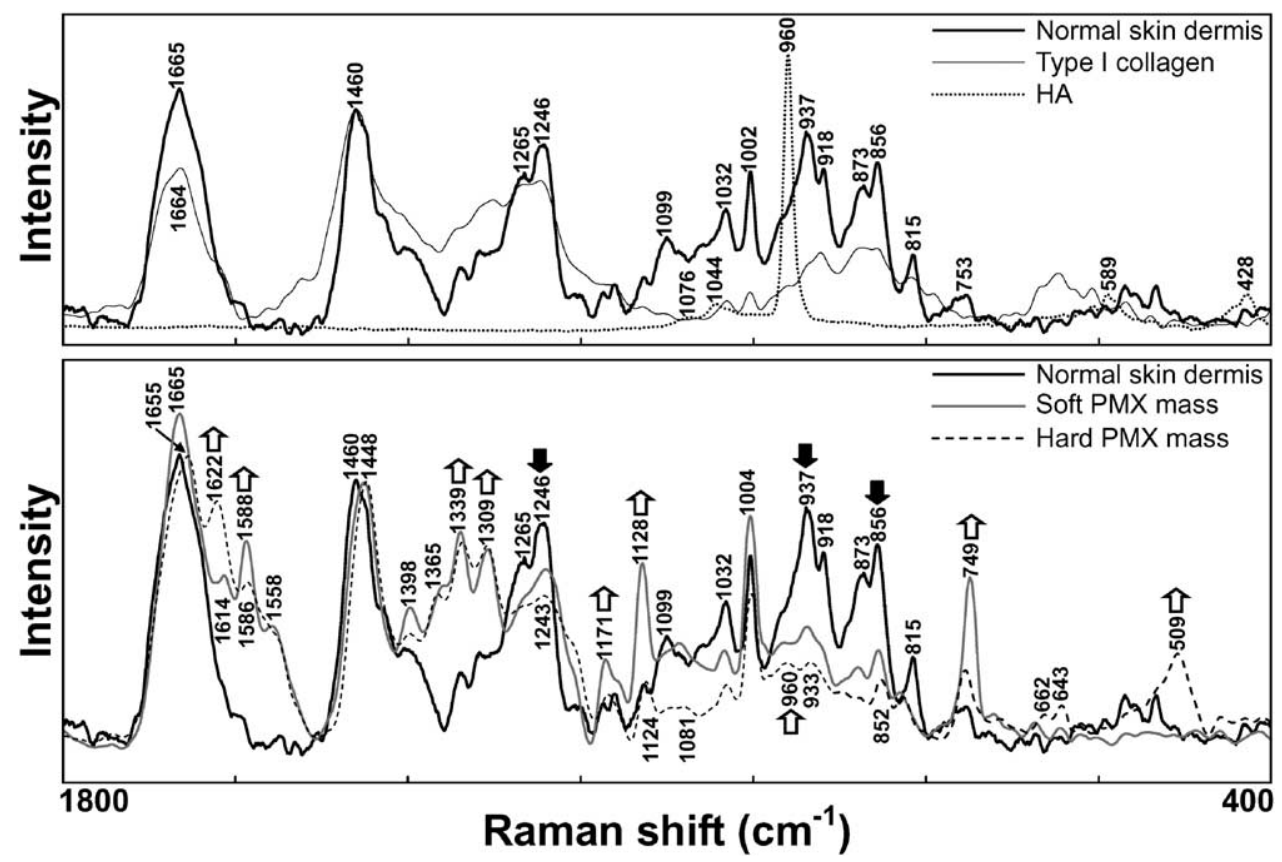

Fig. 12. Raman spectra of the normal skin dermis, type I collagen, HA, soft and hard PMX masses by normalizing the peak intensity within the region of 1460-1448 $\mathrm{cm}^{-1}$ [140]. Key: The decreasing ( $)$ and increasing ( $)$ ) tendencies of specific Raman specks.

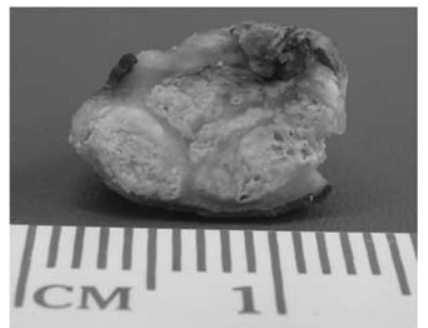

(A) FT-IR spectra

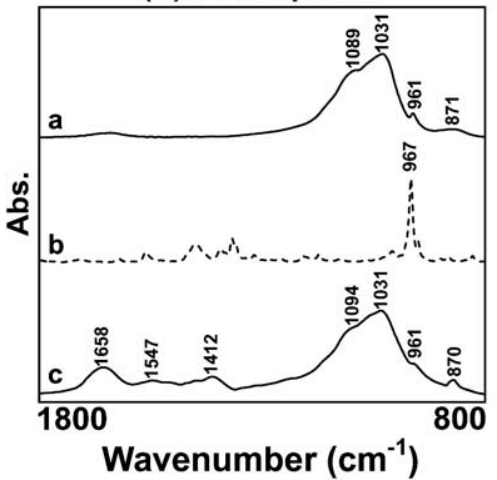

(B) Raman spectra

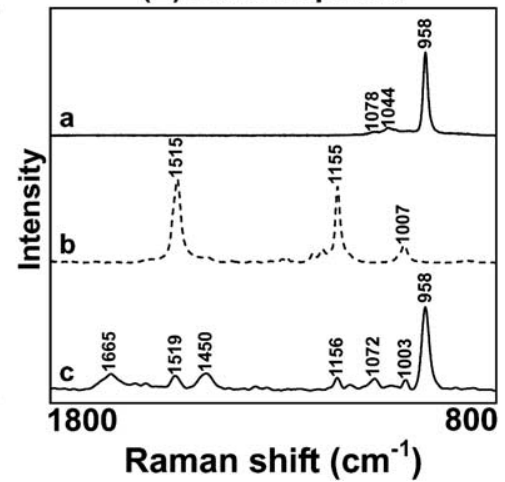

Fig. 13. Surface topograph of the half-cut skin calcified deposit of calcinosis cutis, and FT-IR (A) and Raman (B) spectra for different samples [141]. Key: a, HA reference sample; b, $\beta$-carotene reference sample; $c$, skin calcified deposit. 
H\&E stain and the other for FT-IR and confocal Raman microspectroscopic studies. Our result indicated that the whole skin calcified deposit in the skin lesion was found to be a well developed, mature and hard mass. Several FT-IR absorption bands at 870, 961, 1031, 1547 and $1658 \mathrm{~cm}^{-1}$ were detected in the IR spectrum of deposit. The Raman spectral bands at 1665 and $1450 \mathrm{~cm}^{-1}$ (collagen); 1519 and $1156 \mathrm{~cm}^{-1}$ ( $\beta$-carotene); and 1072 and $958 \mathrm{~cm}^{-1}$ (HA) were also obtained. In this study, we first described that the skin calcified deposit of a calcinosis cutis was composed of collagen, $\beta$-carotene and type-B carbonate HA using FT-IR and Raman microspectroscopic investigations.

\subsection{Identification of brain tumors}

Human pituitary adenomas are the most frequent intracranial neoplasms originating from gland cells of adenohypophysis, which can be responsible for different endocrine and tumoral symptoms. According to the basis of the endocrinological potential of the adenoma, it can be classified into clinically silent and active adenomas [142]. We had used a reflectance FT-IR microspectroscopy to determine the secondary structure and composition of the different human pituitary adenomas. The silent pituitary adenomas exhibited similar protein secondary structure and conformational composition, but active pituitary adenomas revealed different behavior. The reflectance IR spectrum of the silent pituitary adenoma revealed a maximum peak at $1651 \mathrm{~cm}^{-1}$ in the amide I band, whereas the maximum peak was located at 1653 or $1657 \mathrm{~cm}^{-1}$ for active pituitary adenoma. The differences in secondary structure for different human pituitary adenomas might possibly be due to the different protein conformations of the proliferated adenoma tissues and various hormones shared [143].

The benign and malignant astrocytomas were also determined by reflectance FT-IR microspectroscopy [144]. The IR peak maximum in the amide I band of the tissues from recurrent malignant astrocytoma markedly appeared at higher frequency $\left(1655\right.$ or $\left.1663 \mathrm{~cm}^{-1}\right)$, which was significantly different from that of the tissues from benign astrocytoma at $1651 \mathrm{~cm}^{-1}$ and tissues from malignant astrocytoma at $1652 \mathrm{~cm}^{-1}$. Malignant astrocytoma indicated slightly different compositions in the protein secondary structure from benign astrocytoma. A significant increase in $\beta$-turn structure $(1660,1668$, 1682 and $\left.1691 \mathrm{~cm}^{-1}\right)$ but a marked decrease in $\beta$-sheet $\left(1628\right.$ and $\left.1618 \mathrm{~cm}^{-1}\right)$ and in random coil $\left(1645 \mathrm{~cm}^{-1}\right)$ structures were observed in the protein secondary structure of the recurrent malignant astrocytoma. The phenomenon was more pronounced in recurrent malignant astrocytoma pretreated with radiation and chemotherapy. The rapid cell proliferation and cell differentiation of malignant astrocytoma with or without recurrence might be the possible explanations for the different compositions of protein conformational structures.

\subsection{Diagnosis of genetic disorders from scalp hair roots}

\subsubsection{Glucose-6-phosphate dehydrogenase deficiency [145]}

Glucose-6-phosphate dehydrogenase (G6PD) deficiency is an important hereditary metabolic defect that leads to acute hemolytic anemia on ingestion of certain drugs and foods [146]. The clinical symptoms of this genetic disease can be prevented if it is detected early; thus neonatal diagnosis is important. We had demonstrated that FT-IR microspectroscopy could be a rapid and effective diagnostic method to differentiate the scalp hair roots of normal neonates $(n=67)$ into the anagen, catagen or telogen phases of the hair growth cycle (Fig. 14), using IR peak area ratio of $2854 \mathrm{~cm}^{-1} / 2873 \mathrm{~cm}^{-1}$ (A) or $1084 \mathrm{~cm}^{-1} /$ amide II band (B) $(p<0.001)$. Moreover, G6PD-deficient neonates $(n=39)$ could be accurately diagnosed from telogen phase hair roots owing to significant differences in IR peak area ratios 


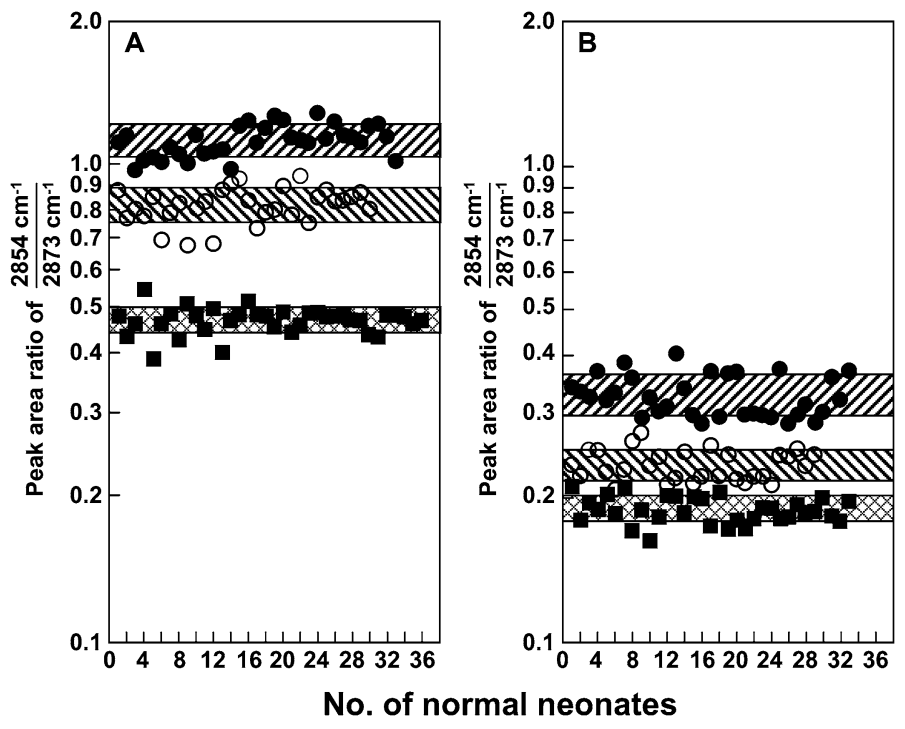

Fig. 14. Peak area ratio of the $2854 \mathrm{~cm}^{-1} / 2873 \mathrm{~cm}^{-1}$ (A) or $1084 \mathrm{~cm}^{-1} /$ amide II band (B) against the number of normal neonates in three different phases of hair growth cycle: $\bullet$, anagen phase; $\bigcirc$, catagen phase; $\mathbf{\square}$, telogen phase [145]. The shaded area represented the normal range.

of $2854 \mathrm{~cm}^{-1} / 2873 \mathrm{~cm}^{-1}$ or $1084 \mathrm{~cm}^{-1} /$ amide II band, compared to normal values in healthy neonates. Hair root analysis seems to be a useful complement to serum and urine analysis in the diagnosis of genetic diseases.

\subsubsection{Phenylketonuria [147]}

Classic phenylketonuria (PKU) is an autosomal recessive disorder caused by failure of hydroxylation of phenylalanine (PA) to tyrosine. When high levels of PA are accumulated, it may cause severe mental retardation [148]. Eight normal newborn infants (PA level $<2 \mathrm{mg} / \mathrm{dl}$ ) and 2 classic PKU infants before and after dietary control with a low PA diet were selected for study. The FT-IR spectra of these hair roots were determined by using FT-IR microspectroscopy. Our findings strongly illustrated that two unique peaks at 1339 and $1169 \mathrm{~cm}^{-1}$ was observed in the hair root of PKU patients before dietary control. Both unique peaks were also verified in the IR spectrum of L-cysteinesulfinic acid. It has been reported that L-cysteinesulfinic acid, as one of the products in the sulfur metabolism of cysteine, can convert to sulfate and being excreted from the urine via transamination [149], although the reason is still unclear. This study reported on the marked difference in FT-IR spectra of hair roots between normal infants and PKU patients before and after dietary control. The evidence of L-cysteinesulfinic acid in hair roots of PKU patients might disappear with dietary control, as shown in Fig. 15.

\subsubsection{Congenital hypothyroidism [150]}

Congenital hypothyroidism $(\mathrm{CH})$ is a common preventable disease mainly caused by thyroid dysgenesis or homonogenesis defects. $\mathrm{CH}$ is characterized by low levels of serum triiodothyronine (T3) and thyroxine (T4), and elevated levels of thyroid- stimulating hormone (TSH) [151]. In the present study, we used FT-IR microspectroscopy to detect the biophysical properties of anagen scalp hair roots of neonates with $\mathrm{CH}$. The serum levels of T3, T4, free T4 (fT4) and TSH for normal ( $n=20)$ and thyroid hormone deficient ( $n=2$, serum TSH level $>10 \mathrm{mU} / \mathrm{l})$ newborns were also determined by radioimmunoassay. The screening results indicated that the serum levels of T3, T4, fT4, and TSH for normal 


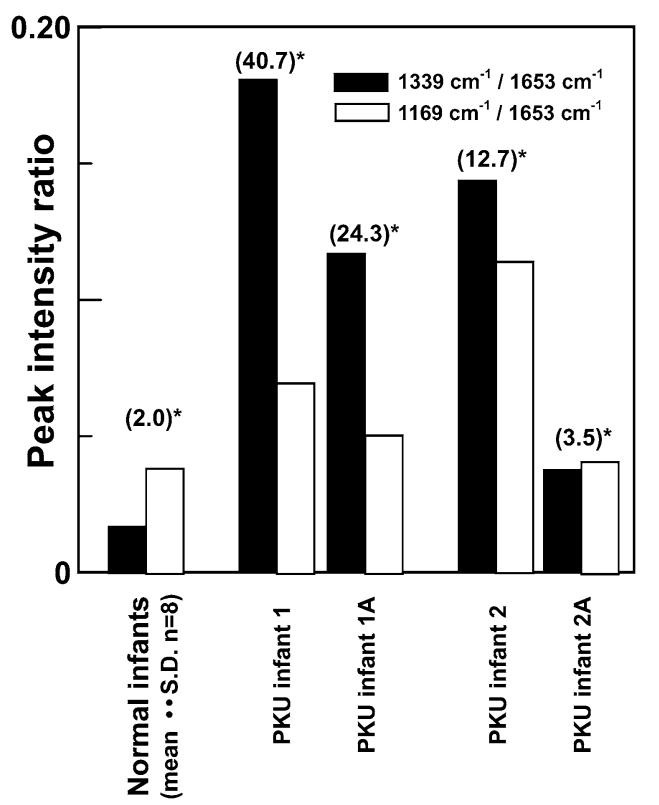

Fig. 15. FT-IR peak intensity ratio of the scalp hair roots for normal and PKU infants [147]. Key: PKU infants 1 and 2: infants before dietary control. PKU infant 1A: infant 1 after dietary control for 3 hrs. PKU infant 2A: infant 2 after dietary control for 1 week. *Plasma PA level.

newborns were all within the normal limit. However, patients 1 and 2 had lower T4 and fT4 levels but the highest TSH level ( $>60$-fold to normal value), and were clinically diagnosed to be the typical severe neonatal hypothyroidism. The FT-IR results indicated that the lower composition near $1053 \mathrm{~cm}^{-1}$ (also assigned to the aromatic iodide stretching band) in the IR spectra of the hair roots for $\mathrm{CH}$ patients was directly associated with the lower serum level of T4 and fT4, and the elevated TSH levels.

\subsection{Detection of benign prostatic hyperplasia}

\subsubsection{Epithelial and stromal growth in the human $B P H$ [152]}

Benign prostatic hyperplasia (BPH) is one of the most common diseases in elderly men. It describes an overgrowth of the epithelium and stroma in the human prostate, in which both tissues proliferate at different rates [153]. We utilized a reflectance FT-IR microspectroscopy to pathologically image and examine the structural changes of the molecular constituents in BPH tissues. Two successive thin tissue slices were obtained by cutting the tissue with a microtome: one unstained slice was used for FT-IR microspectroscopic analysis and the other stained slice was used for position referencing. The result showed that the IR maximum peak in the amide I band for BPH epithelial tissue was located at $1638 \mathrm{~cm}^{-1}$ assigned to the contribution of random coil and $\beta$-sheet structures. However, an intense IR absorption peak in amide I band was at $1630 \mathrm{~cm}^{-1}$ for BPH stromal tissue due to the predominant $\beta$-sheet structure. The higher peak intensity of several IR bands at 1337, 1281, 1238, 1206, 1055 and $1034 \mathrm{~cm}^{-1}$, assigned to the $\mathrm{C}-\mathrm{O}$ stretching mode of collagen, was observed in BPH stromal tissue (Fig. 16). This suggested that the higher content of collagen was observed in the stromal tissue than in the epithelial tissue of the proliferous BPH. 


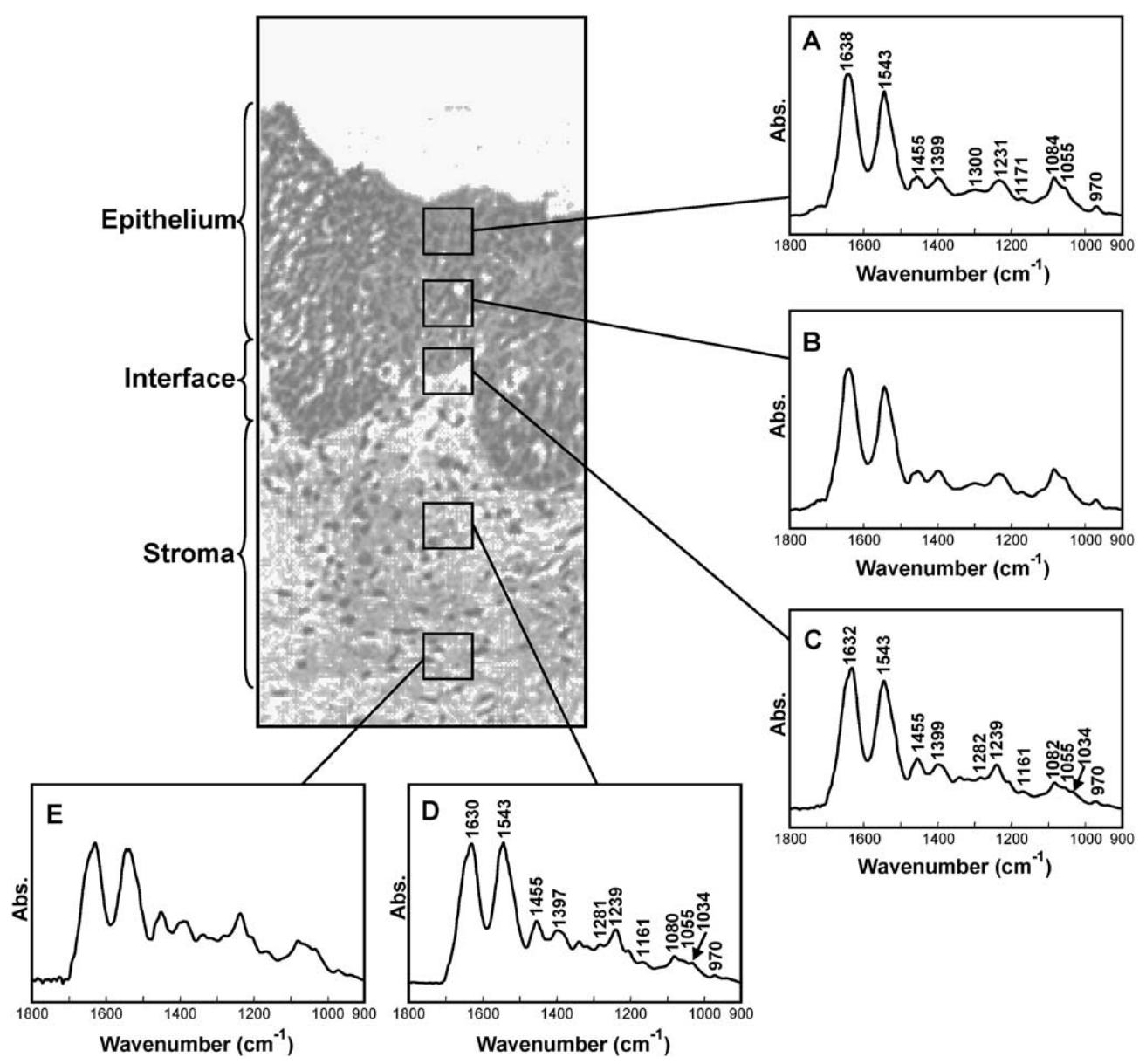

Fig. 16. Optical micrograph of a stained BPH tissue biopsy and the corresponding reflectance FT-IR spectra of the unstained same tissue at five different sites [152].

\subsubsection{In vitro simulation of $B P H$ thermotherapy $[154,155]$}

The thermotherapy has been successfully used to treat the BPH patients by using a transurethral prostatic heating device. We had used a novel system by combining the microscopic FT-IR spectroscopy and differential scanning calorimetry (DSC) to non-isothermally (from 25 to $60^{\circ} \mathrm{C}$ ) or isothermally $\left(47^{\circ} \mathrm{C}\right.$, $3 \mathrm{~h}$ ) simulate the clinical BPH thermotherapy, in vitro. The protein conformational structure of the epithelium and stroma of BPH tissue during both thermal treatments were also investigated. The results revealed that the isolated epithelium and stroma of BPH tissue could slightly change their secondary structure from $\alpha$-helix to $\beta$-structure in the temperature range of $25-60^{\circ} \mathrm{C}$, like the other thermal-sensitive protein. However, this thermal-induced conversion behavior in the stroma was less sensitive than that in the epithelium during thermal treatment. The different thermal response between the epithelium and stroma of BPH might be due to the different constitutions in the epithelium and stroma of BPH. On the other hand, no significant change was evidenced in the secondary structure for each sample either before or after isothermal study (Fig. 17), suggesting the integrality and safety of BPH thermotherapy in a $47^{\circ} \mathrm{C}$ for $3 \mathrm{~h}$ treatment course. 


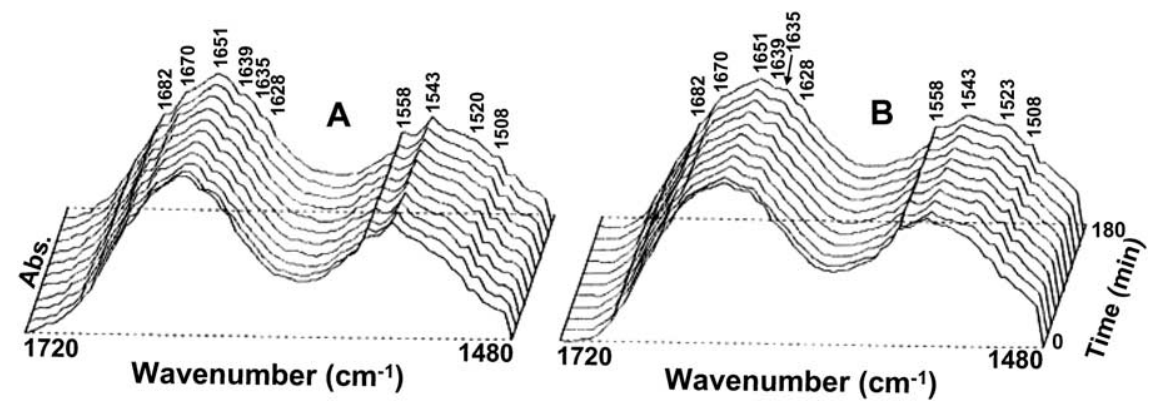

Fig. 17. Three-dimensional plots of FT-IR spectra of epithelium (A) and stroma (B) of BPH with respect to heating time [155].

\subsubsection{Transurethral resection of the prostate [156]}

Transurethral resection of the prostate (TURP) is one of the gold-standard surgical treatments for BPH to alleviate the symptoms and signs of urinary outflow obstruction and to improve quality of life. In the process of TURP, the higher electrosurgical energy via cutting loop was used to remove the prostatic tissue piece. Here, the ATR/FT-IR microspectroscopy was applied to study the effect of the higher electric cutting heat of TURP treatment on the protein conformation of stroma and epithelium in BPH tissue. The tissue obtained by a non-heating process of prostatic needle biopsy was used as a control. The results indicated a predominantly higher proportion of $\beta$-sheet conformation of the epithelium or stroma in $\mathrm{BPH}$ tissue at 1633 or $1630 \mathrm{~cm}^{-1}$ in the amide I band, but after treatment with TURP both IR maximum peaks shifted to 1644 or $1646 \mathrm{~cm}^{-1}$ due to random coil structure, respectively. Our study showed that TURP might convert the protein conformational structure of both epithelium and stroma in BPH tissue from $\beta$-sheet to random coil due to the higher temperature used. This conformational interconversion might possibly relate to the occurrence of complications or the alteration of functional integrity of $\mathrm{BPH}$.

\subsection{Diagnosis of interstitial cystitis after PST}

Interstitial cystitis (IC) is a chronic bladder disorder occurring predominantly in women. There is lack of a uniform, definitive and worldwide standard technique for clinical diagnosis of IC [157]. Twenty-two participants were screened by clinical features, history, potassium sensitivity test (PST) and urodynamic evaluations. The freeze-dried water samples voided from all the participants after PST were directly determined by using a confocal micro-Raman spectroscopy to investigate their chemical compositions. Participants with or without IC symptom were separated into control and clinical groups, according to the above examinations. The participants in the clinical group were further divided into mild and severe subgroups by PST. A significant increase in urinary frequency but a marked reduction in bladder capacity, maximum cystometric capacity and maximum voiding flow rate were obtained for clinical group of IC participants, as compared with the result of control group $(p<0.05)$. The symptom of urinary pain and urgency was also significant difference between the mild and severe subgroups $(p<0.05)$. The Raman result indicated that the Raman band near $1003-1005 \mathrm{~cm}^{-1}$ assigned to phenylalanine was observed for control groups and mild subgroups, but the Raman band at $1010 \mathrm{~cm}^{-1}$ due to tryptophan was found for severe subgroups (Fig. 18). This study first suggested a possible application of Raman microspectroscopy to certify again the results of PST for IC diagnosis [158]. Phenylalanine or tryptophan seemed to act as a biomarker to assist the diagnosis of IC after PST. Particularly, the appearance of tryptophan might be used to discriminate the severity of IC symptom. 

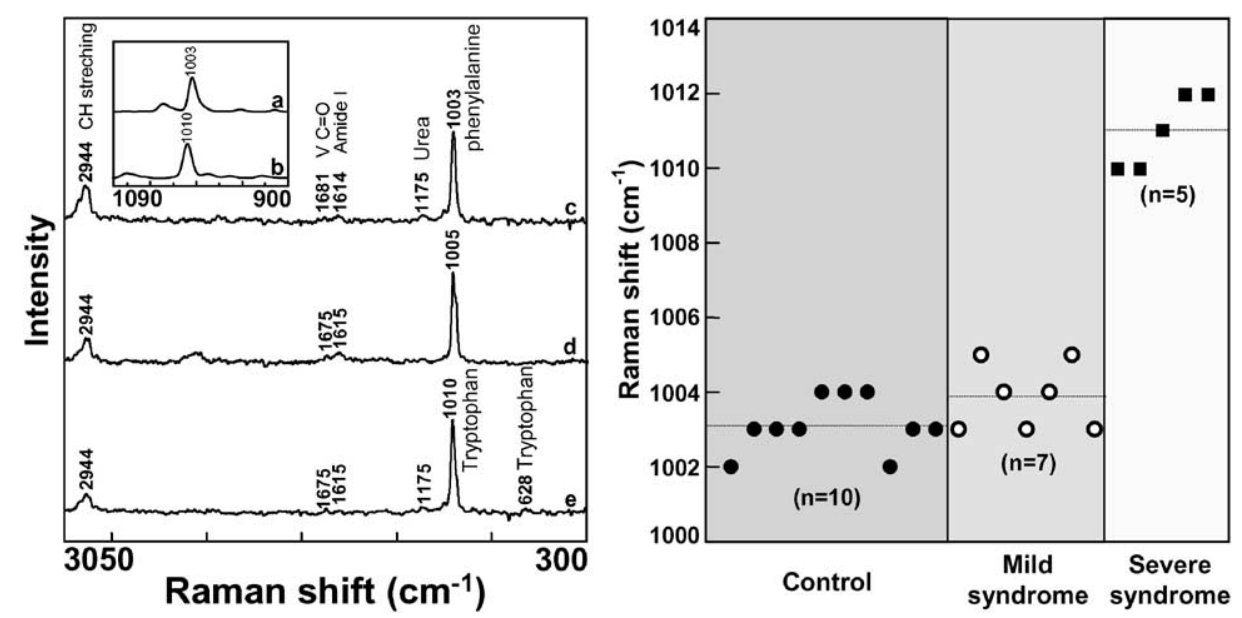

Fig. 18. Raman spectra and Raman shift of different samples [158]. Key: a, intact phenylalanine; b, intact tryptophan; c, freeze-dried water sample of control groups; d, freeze-dried water sample of mild subgroups; e, freeze-dried water sample of severe subgroups.

\section{Conclusions and future prospects}

FT-IR and Raman vibrational spectroscopic techniques have been extensively used to diagnose and differentiate the chemical differences between diseased and normal tissues based on the IR absorption or Raman scattering spectra via the molecular vibrations of biosamples. Recently, several new improvements are now being developed. Both vibrational microspectroscopies coupling with the modern fiberoptic probes have been designed to directly reach less assessable organs and in vivo measure the spectra of various levels of cells, tissues and organs in their most natural state in quite a few seconds, in which the tissue without the need of biopsy can be easily detected. The detection of atherosclerosis and cervical cancers has been successfully performed $[159,160]$. Another new design for vibrational spectroscopic techniques is a combination of FT-IR and Raman system. This FT-IR/Raman combination microprobe system enables a simultaneous examination of one fixed sample area by both techniques, without the need for any sample positioning or instrument adjustment. This is a single microscope simultaneously coupling to an IR interferometer and a Raman spectrograph, in which the IR beams and laser are coincident at the sample and provide the spectral information of the same material site $[161,162]$.

Although there are several advantages for both vibrational microspectroscopies, whether the spectral information being able to satisfy clinical diagnostic requirements and assist the physicians' diagnosis and treatment plan for patients is not yet available. Thus further investigations and improvements of FT-IR and/or Raman vibrational microspectroscopy are necessary to make these approaches in vivo applicable to routinely use in clinical analysis at a much earlier disease stage [18,163-166].

\section{Acknowledgements}

The authors would like to thank Drs. Lee L.S. and Liu H.C. (Neurological Institute), Drs. Wu C.W., Hsu H.S. and Lin A.T.L. (Surgery Department), Drs. Lee S.M. and Chen K.H. (Ophthalmology Department), Dr. Niu D.M. (Pediatrics Department), Drs. Liu M.T. and Liu H.N. (Dermatology Department), Dr. Yu K.J. (Obstetrics and Gynecology Department), and Dr. Chi C.W. (Med. Res. Res. Department) of 
our hospital's colleagues for their supporting the human samples and kindly comments. We would also like to acknowledge Drs. Wang S.L., Yang D.M. and Cheng Y.D., and Misses Liang R.C., Cheng C.L., Hsieh T.F. and Lin H.T., and Mr. Tu C.P. for technical assistances in much sample preparation and data collection.

\section{References}

[1] J.G. Grasselli, M. Mehicic and J.R. Mooney, Applications of infrared and Raman spectroscopy in industry, Fresenius' J. Anal. Chem. 324 (1986), 537-543.

[2] N.B. Colthup, L.H. Daly and S.E. Wiberely, Introducation to IR and Raman Spectroscopy, 3rd edn, Academic Press Inc., New York, 1990.

[3] M.D. Fayer, Ultrafast Infrared and Raman Spectroscopy, Practical spectroscopy series, vol. 26, Marcel Dekker, Inc., New York, 2001.

[4] R.J. Meier, Vibrational spectroscopy: a 'vanishing' discipline?, Chem. Soc. Rev. 34 (2005), 743-752.

[5] F. Adar, G. leBourdon, J. Reffner and A. Whitley, FT-IR and Raman microscopy on a united platform: A technology whose time has come, Spectroscopy Magazine 18(2) (2003), 34-40.

[6] C. Krafft, Bioanalytical applications of Raman spectroscopy, Anal. Bioanal. Chem. 378 (2004), 60-62.

[7] H.U. Gremlich and B. Yan, Infrared and Raman Spectroscopy of Biological Materials, Marcel Dekker, Inc., New York, 2001.

[8] A.M.A. Pistorius, Biochemical applications of FT-IR spectroscopy, Spectroscopy Europe 7(4) (1995), 8-15.

[9] B.C. Smith, Foundamentals of Fourier Transform Infrared Spectroscopy, CRC Press, 1996.

[10] D.L.B. Wetzel and S.M. LeVine, Fourier Transform Infrared (FTIR) Microspectroscopy: A new molecular dimension for tissue or cellular imaging and in situ chemical analysis, Cell. Mol. Biol. (specical issue) 44 (1998), 1-272.

[11] M.J. Walsh, M.J. German, M. Singh, H.M. Pollock, A. Hammiche, M. Kyrgiou, H.F. Stringfellow, E. Paraskevaidis, P.L. Martin-Hirsch and F.L. Martin, IR microspectroscopy: potential applications in cervical cancer screening, Cancer Lett. 246 (2007), 1-11.

[12] D.I. Ellis and R. Goodacre, Metabolic fingerprinting in disease diagnosis: biomedical applications of infrared and Raman spectroscopy, Analyst 131 (2006), 875-885.

[13] C. Krafft and V. Sergo, Biomedical applications of Raman and infrared spectroscopy to diagnose tissues, Spectroscopy 20 (2006), 195-218.

[14] H.H. Mantsch, L.P. Choo-Smith and R.A. Shaw, Vibrational spectroscopy and medicine: an alliance in the making, Vibrational Spectro 30 (2002), 31-41.

[15] T.W. Koo, A.J. Berger, I. Itzkan, G. Horowitz, and M.S. Feld, Reagentless blood analysis by near-infrared Raman spectroscopy, Diabetes Technol. Therap. 1 (1999), 153-157.

[16] R.J. Erckens, F.H. Jongsma, J.P. Wicksted, F. Hendrikse, W.F. March and M. Motamedi, Raman spectroscopy in ophthalmology: from experimental tool to applications in vivo, Lasers Med. Sci. 16 (2001), 236-252.

[17] A. Boskey and R. Mendelsohn, Infrared analysis of bone in health and disease, J. Biomed. Opt. 10 (2005), 031102.

[18] W. Petrich, Mid-infrared and Raman spectroscopy for medical diagnostics, Appl. Spectro. Rev. 36 (2001), 181-237.

[19] U.P. Agarwal, Raman imaging to investigate ultrastructure and composition of plant cell walls: distribution of lignin and cellulose in black spruce wood (Picea mariana), Planta 224 (2006), 1141-1153.

[20] A. Whitley and F. Adar, Confocal spectral imaging in tissue with contrast provided by Raman vibrational signatures, Cytometry A. 69 (2006), 880-887.

[21] D.C. Fernandez, R. Bhargava, S.M. Hewitt and I.W. Levin, Infrared spectroscopic imaging for histopathologic recognition, Nat. Biotechnol. 23 (2005), 469-474.

[22] C. Petibois and G. Deleris, Chemical mapping of tumor progression by FT-IR imaging: towards molecular histopathology, Trends Biotechnol. 24 (2006), 455-462.

[23] D. Chenery and H. Bowring, Infrared and Raman spectroscopic imaging in biosciences. Spectroscopy Europe 15(4) (2003), 8-14.

[24] Unpublished data.

[25] E.N. Lewis, P.J. Treado, R.C. Reeder, G.M. Story, A.E. Dowrey, C. Marcoot and I.W. Levin, Fourier transform spectroscopic imaging using an infrared focal-plane array detector, Anal. Chem. 67 (1995), 3377-3381.

[26] P. Heraud, S. Caine, G. Sanson, P.R. Gleadow, B.R. Wood and D. McNaughton, Focal plane array infrared imaging: a new way to analyse leaf tissue, New Phytol. 173 (2007), 216-225.

[27] E. Gazi, J. Dwyer, P. Gardner, A. Ghanbari-Siahkali, A.P. Wade, J. Miyan, N.P. Lockyer, J.C. Vickerman, N.W. Clarke, J.H. Shanks, L.J. Scott, C.A. Hart and M. Brown, Applications of Fourier transform infrared microspectroscopy in studies of benign prostate and prostate cancer. A pilot study, J. Pathol. 201 (2003), 99-108. 
[28] R. K. Sahu, S. Argov, A. Salman, M. Huleihel, N. Grossman, Z. Hammody, J. Kapelushnik and S. Mordechai, Characteristic absorbance of nucleic acids in the Mid-IR region as possible common biomarkers for diagnosis of malignancy, Technol. Cancer Res. Treat. 3 (2004), 629-638.

[29] E.P. Paschalis, E. DiCarlo, F. Betts, P. Sherman, R. Mendelsohn and A.L. Boskey, FTIR microspectroscopic analysis of human osteonal bone, Calcif. Tissue Int. 59 (1996), 480-487.

[30] D. Faibish, A. Gomes, G. Boivin, I. Binderman and A. Boskey, Infrared imaging of calcified tissue in bone biopsies from adults with osteomalacia, Bone 36 (2005), 6-12.

[31] A. Carden and M.D. Morris, Application of vibrational spectroscopy to the study of mineralized tissues, J. Biomed. Opt. 5 (2000), 259-268.

[32] A. Wang, K. Kuebler, B. Jolliff and L.A. Haskin, Mineralogy of a Martian meteorite as determined by Raman spectroscopy, J. Raman Spectro. 35 (2004), 504-514.

[33] L.G. Thygesen, M.M. Lokke, E. Micklander and S.B. Engelsen, Vibrational microspectroscopy of food. Raman vs. FT-IR, Trends in Food Sci. Technol. 14 (2003), 50-57.

[34] F. Adar, Evolution and revolution of Raman instrumentation. Applications of available technologies to spectroscopy and microscopy, in Handbook of Raman Spectroscopy, I.R. Lewis and H.G.M. Edwards, eds, Marcel Dekker, New York, 2001, pp. 11-40.

[35] G. Singh, C. Creely, G. Volpe, H. Grotsch and D. Petrov, Raman spectroscopy of a single living cell in environmentally stressed conditions, Proc. SPIE 5930 (2005), 32-42.

[36] C. Otto, N.M. Sijtsema and J. Greve, Confocal Raman microspectroscopy of the activation of single neutrophilic granulocytes, Eur. Biophys. J. 27 (1998), 582-589.

[37] A. Hynes, D.A. Scott, A. Man, D.L. Singer, M.G. Sowa and K.Z. Liu, Molecular mapping of periodontal tissues using infrared microspectroscopy, BMC Med. Imaging 5 (2005), 2.

[38] V.N. Bagratashvili, N.V. Bagratashvili, N.Yu Ignat'eva, V.V.Lunin, T.E. Grokhovskaya, S.V. Averkiev, A.P. Sviridov and G.Sh. Shakh, Structural changes in connective tissues caused by a moderate laser heating, Quantum Electron. 32 (2002), 913-916.

[39] L.P. Choo, K. Maquelin, T. van Vreeswijk, H.A. Bruining, G.J. Puppels, N.A. Ngo Thi, C. Kirschner, D. Naumann, D. Ami, A.M. Villa, F. Orsini, S.M. Doglia, H. Lamfarraj, G.D. Sockalingum, M. Manfait, P. Allouch and H.P. Endtz, Investigating microbial (micro)colony heterogeneity by vibrational spectroscopy, Appl. Environ. Microbiol. 67 (2001), 1461-1469.

[40] S. Sivakesava, J. Irudayaraj and A. Demirci, Monitoring a bioprocess for ethanol production using FT-MIR and FTRaman spectroscopy, J. Indus. Microbiol. Biotechnol. 26 (2001), 185-190.

[41] S. Derek, Fourier transform infrared microspectroscopy of plant tissues, Appl. Spectrosc. 50 (1996), 357-365.

[42] K. Dokken, L. Davis and N. Marinkovic, Use of Fourier transform infrared microspectroscopy in plant growth and development, Appl. Spectrosc. Rev. 40 (2005), 301-326.

[43] K. Merrett, R.M. Cornelius, W.G. McClun, L.D. Unsworth and H. Sheardown, Surface analysis methods for characterizing polymeric biomaterials, J. Biomater. Sci. Polym. Ed. 13 (2002), 593-621.

[44] T. Kasuga, Bioactive calcium pyrophosphate glasses and glass-ceramics, Acta Biomater. 1 (2005), 55-64.

[45] C.M. Hodges and J. Akhavan, The use of fourier transform Raman spectroscopy in the forensic identification of illicit drugs and explosives, Spectrochimica Acta 40A (1990), 303-307.

[46] K.S. Kalasinsky, Drug distribution in human hair by infrared microscopy, Cell. Mol. Biol. 44 (1998), 81-87.

[47] F. Bonnier, S. Rubin, L. Venteo, C.M. Krishna, M. Pluot, B. Baehrel, M. Manfait and G.D. Sockalingum, In-vitro analysis of normal and aneurismal human ascending aortic tissues using FT-IR microspectroscopy, Biochim. Biophys. Acta 1758 (2006), 968-973.

[48] X. Bi, X. Yang, M.P. Bostrom and N.P. Camacho, Fourier transform infrared imaging spectroscopy investigations in the pathogenesis and repair of cartilage, Biochim. Biophys. Acta 1758 (2006), 934-941.

[49] J.Mordehai, J. Ramesh, M. Huleihel, Z. Cohen, O. Kleiner, M. Talyshinsky, V. Erukhimovitch, A. Cahana, A. Salman, R.K. Sahu, H. Guterman and S. Mordechai, Studies on acute human infections using FTIR microspectroscopy and cluster analysis, Biopolymers 73 (2004), 494-502.

[50] P. Lasch, W. Haensch, D. Naumann and M. Diem, Imaging of colorectal adenocarcinoma using FT-IR microspectroscopy and cluster analysis, Biochim. Biophys. Acta 1688 (2004), 176-186.

[51] J.S. Wang, J.S. Shi, Y.Z. Xu, X.Y. Duan, L. Zhang, J. Wang, L.M. Yang, S.F. Weng and J.G. Wu, FT-IR spectroscopic analysis of normal and cancerous tissues of esophagus, World J. Gastroenterol. 9 (2003), 1897-1899.

[52] J. Ramesh, J. Kapelushnik, J. Mordehai, A. Moser, M. Huleihel, V. Erukhimovitch, C. Levi and S. Mordechai, Novel methodology for the follow-up of acute lymphoblastic leukemia using FTIR microspectroscopy, J. Biochem. Biophys. Methods 51 (2002), 251-261.

[53] E.P. Paschalis, E. DiCarlo, F. Betts, P. Sherman, R. Mendelsohn and A.L. Boskey, FTIR microspectroscopic analysis of human osteonal bone, Calcif. Tissue Int. 59 (1996), 480-487. 
[54] Y.J. Chen, Y.D. Cheng, H.Y. Liu, P.Y. Lin, C.S. Wang, Observation of biochemical imaging changes in human pancreatic cancer tissue using Fourier-transform infrared microspectroscopy, Chang Gung Med. J. 29 (2006), 518-527.

[55] B.R. Wood, L. Chiriboga, H. Yee, M.A. Quinn, D. McNaughton and M. Diem, Fourier transform infrared (FTIR) spectral mapping of the cervical transformation zone, and dysplastic squamous epithelium, Gynecol. Oncol. 93 (2004), 59-68.

[56] A. Salman, S. Argov, J. Ramesh, J. Goldstein, I. Sinelnikov, H. Guterman and S. Mordechai, FT-IR microscopic characterization of normal and malignant human colonic tissues, Cell. Mol. Biol. 47 (2001), 159-166.

[57] Y.J. Chen, Y.W. Hsieh, Y.D. Cheng and C.C. Liao, Study on the secondary structure of protein in amide I band from human colon cancer tissue by Fourier-transform infrared spectroscopy, Chang Gung Med. J. 24 (2001), 541-546.

[58] K. Yano, S. Ohoshima, Y. Gotou, K. Kumaido, T. Moriguchi and H. Katayama, Direct measurement of human lung cancerous and noncancerous tissues by fourier transform infrared microscopy: can an infrared microscope be used as a clinical tool? Anal. Biochem. 287 (2000), 218-225.

[59] M. Garcia-Closas, S.E. Hankinson, S. Ho, D.C. Malins, N.L. Polissar, S.N. Schaefer, Y. Su and M.A. Vinson, Factors critical to the design and execution of epidemiologic studies and description of an innovative technology to follow the progression from normal to cancer tissue, J. Natl. Cancer Inst. Monogr. 27 (2000), 147-156.

[60] J.A. Homan, J.D. Radel, D.D. Wallace, D.L. Wetzel and S.M. Levine, Chemical changes in the photoreceptor outer segments due to iron induced oxidative stress: analysis by Fourier transform infrared (FT-IR) microspectroscopy, Cell. Mol. Biol. 46 (2000), 663-672.

[61] S.M. LeVine and D.L. Wetzel, Chemical analysis of multiple sclerosis lesions by FT-IR microspectroscopy, Free Radic. Biol. Med. 25 (1998), 33-41.

[62] J.M. Gentner, E. Wentrup-Byrne, P.J. Walker and M.D. Walsh, Comparison of fresh and post-mortem human arterial tissue: an analysis using FT-IR microspectroscopy and chemometrics, Cell. Mol. Biol. 44 (1998), 251-259.

[63] R.K. Dukor, M.N. Liebman and B.L. Johnson, A new, non-destructive method for analysis of clinical samples with FT-IR microspectroscopy. Breast cancer tissue as an example, Cell. Mol. Biol. 44 (1998), 211-217.

[64] P. Lasch and D. Naumann, FT-IR microspectroscopic imaging of human carcinoma thin sections based on pattern recognition techniques, Cell. Mol. Biol. 44 (1998), 189-202.

[65] L.P. Choo, D.L. Wetzel, W.C. Halliday, M. Jackson, S.M. LeVine and H.H. Mantsch, In situ characterization of betaamyloid in Alzheimer's diseased tissue by synchrotron Fourier transform infrared microspectroscopy, Biophys. J. 71 (1996), 1672-1679.

[66] K. Yano, S. Ohoshima, Y. Shimizu, T. Moriguchi and H. Katayama, Evaluation of glycogen level in human lung carcinoma tissues by an infrared spectroscopic method, Cancer Lett. 110 (1996), 29-34.

[67] I. About and T.A. Mitsiadis, Molecular aspects of tooth pathogenesis and repair: in vivo and in vitro models, Adv. Dent. Res. 15 (2001), 59-62.

[68] R. Manoharan, J.J. Baraga, R.P. Rava, R.R. Dasari, M. Fitzmaurice and M.S. Feld, Biochemical analysis and mapping of atherosclerotic human artery using FT-IR microspectroscopy, Atherosclerosis 103 (1993), 181-193.

[69] C. Krafft, L. Shapoval, S.B. Sobottka, G. Schackert and R. Salzer, Identification of primary tumors of brain metastases by infrared spectroscopic imaging and linear discriminant analysis. Technol, Cancer Res. Treat. 5 (2006), 291-298.

[70] W. Hubner, A. Blume, R. Pushnjakova, Y. Dekhtyar and H.J. Hein, The influence of X-ray radiation on the mineral/organic matrix interaction of bone tissue: an FT-IR microscopic investigation, Int. J. Artif. Organs 28 (2005), 66-73.

[71] J.I. Chang, Y.B. Huang, P.C. Wu, C.C. Chen, S.C. Huang and Y.H. Tsai, Characterization of human cervical precancerous tissue through the Fourier transform infrared microscopy with mapping method, Gynecol. Oncol. 91 (2003), 577-583.

[72] E.P. Paschalis, A.L. Boskey, M. Kassem and E.F. Eriksen, Effect of hormone replacement therapy on bone quality in early postmenopausal women, J. Bone Miner. Res. 18 (2003), 955-959.

[73] S. Argov, J. Ramesh, A. Salman, I. Sinelnikov, J. Goldstein, H. Guterman and S. Mordechai, Diagnostic potential of Fourier-transform infrared microspectroscopy and advanced computational methods in colon cancer patients, J. Biomed. Opt. 7 (2002), 248-254.

[74] U. Bindig, H. Winter, W. Wasche, K. Zelianeos and G. Muller, Fiber-optical and microscopic detection of malignant tissue by use of infrared spectrometry, J. Biomed. Opt. 7 (2002), 100-108.

[75] L.M. Miller, V. Vairavamurthy, M.R. Chance, R. Mendelsohn, E.P. Paschalis, F. Betts and A.L. Boskey, In situ analysis of mineral content and crystallinity in bone using infrared micro-spectroscopy of the $\nu_{4} \mathrm{PO}_{4}^{3-}$ vibration, Biochim. Biophys. Acta 1527 (2001), 11-19.

[76] M. Diem, L. Chiriboga and H. Yee, Infrared spectroscopy of human cells and tissue. VIII. Strategies for analysis of infrared tissue mapping data and applications to liver tissue, Biopolymers 57 (2000), 282-290.

[77] D.L. Wetzel, D.N. Slatkin and S.M. Levine, FT-IR microspectroscopic detection of metabolically deuterated compounds in the rat cerebellum: a novel approach for the study of brain metabolism, Cell. Mol. Biol. 44 (1998), 15-27.

[78] C. Krafft, R. Salzer, G. Soff and M. Meyer-Hermann, Identification of B and T cells in human spleen sections by infrared microspectroscopic imaging, Cytometry A 64 (2005), 53-61.

[79] G. Steiner, A. Shaw, L.P. Choo-Smith, M.H. Abuid, G. Schackert, S. Sobottka, W. Steller, R. Salzer and H.H. Mantsch, Distinguishing and grading human gliomas by IR spectroscopy, Biopolymers 72 (2003), 464-471. 
[80] M. Kakei, H. Nakahara, M. Kumegawa, M. Yoshikawa and S. Kunii, Demonstration of the central dark line in crystals of dental calculus, Biochim. Biophys. Acta 1524 (2000), 189-195.

[81] C. Krafft, S.B. Sobottka, G. Schackert and R. Salzer, Analysis of human brain tissue, brain tumors and tumor cells by infrared spectroscopic mapping, Analyst 129 (2004), 921-925.

[82] W. Steller, J. Einenkel, L.C. Horn, U.D. Braumann, H. Binder, R. Salzer and C. Krafft, Delimitation of squamous cell cervical carcinoma using infrared microspectroscopic imaging, Anal. Bioanal. Chem. 384 (2006), 145-154.

[83] C.M. Krishna, G.D. Sockalingum, R.A. Bhat, L. Venteo, P. Kushtagi, M. Pluot and M. Manfait, FTIR and Raman microspectroscopy of normal, benign, and malignant formalin-fixed ovarian tissues, Anal. Bioanal. Chem. 387 (2007), 10.1007/s00216-006-0827-1.

[84] E. Gazi, M. Baker, J. Dwyer, N.P. Lockyer, P. Gardner, J.H. Shanks, R.S. Reeve, C.A. Hart, N.W. Clarke and M.D. Brown, A correlation of FTIR spectra derived from prostate cancer biopsies with gleason grade and tumour stage, Eur. Urol. 50 (2006), 750-761.

[85] M.J. German, A. Hammiche, N. Ragavan, M.J. Tobin, L.J. Cooper, S.S. Matanhelia, A.C. Hindley, C.M. Nicholson, N.J. Fullwood, H.M. Pollock and F.L. Martin, Infrared spectroscopy with multivariate analysis potentially facilitates the segregation of different types of prostate cell, Biophys. J. 90 (2006), 3783-3795.

[86] A. Tfayli, O. Piot, A. Durlach, P. Bernard and M. Manfait, Discriminating nevus and melanoma on paraffin-embedded skin biopsies using FTIR microspectroscopy, Biochim. Biophys. Acta 1724 (2005), 262-269.

[87] Z. Hammody, R.K. Sahu, S. Mordechai, E. Cagnano and S. Argov, Characterization of malignant melanoma using vibrational spectroscopy, Scientific World J. 5 (2005), 173-182.

[88] S. Mordechai, R.K. Sahu, Z. Hammody, S. Mark, K. Kantarovich, H. Guterman, A. Podshyvalov, J. Goldstein and S. Argov, Possible common biomarkers from FTIR microspectroscopy of cervical cancer and melanoma, J. Microsc. 215 (2004), 86-91.

[89] S. Argov, R.K. Sahu, E. Bernshtain, A. Salman, G. Shohat, U. Zelig and S. Mordechai, Inflammatory bowel diseases as an intermediate stage between normal and cancer: a FTIR-microspectroscopy approach, Biopolymers 75 (2004), 384-392.

[90] P.J. Caspers, G.W. Lucassen and G.J. Puppels, Combined in vivo confocal Raman spectroscopy and confocal microscopy of human skin, Biophys. J. 85 (2003), 572-580.

[91] J.J. Duindam, G.F. Vrensen, C. Otto and J. Greve, Cholesterol, phospholipid, and protein changes in focal opacities in the human eye lens, Invest. Ophthalmol. Vis. Sci. 39 (1998), 94-103.

[92] M.V. Chowdary, K.K. Kumar, J. Kurien, S. Mathew and C.M. Krishna, Discrimination of normal, benign and malignant breast tissues by Raman spectroscopy, Biopolymers 83 (2006), 556-569.

[93] N.J. Bauer, F. Hendrikse and W.F. March, In vivo confocal Raman spectroscopy of the human cornea, Cornea 18 (1999), 483-488.

[94] A.P. Oliveira, R.A. Bitar, L. Silveira, R.A. Zangaro and A.A. Martin, Near-infrared Raman spectroscopy for oral carcinoma diagnosis, Photomed. Laser Surg. 24 (2006), 348-353.

[95] P.O. Andrade, R.A. Bitar, K. Yassoyama, H. Martinho, A.M. Santo, P.M. Bruno and A.A. Martin, Study of normal colorectal tissue by FT-Raman spectroscopy, Anal. Bioanal, Chem. 387 (2007), 10.1007/s00216-006-0819-1.

[96] K. Das, N. Stone, C. Kendall, C. Fowler and J. Christie-Brown, Raman spectroscopy of parathyroid tissue pathology, Lasers Med. Sci. 21 (2006), 192-197.

[97] N. Stone, P. Stavroulaki, C. Kendall, M. Birchall, H. Barr, Raman spectroscopy for early detection of laryngeal malignancy: preliminary results, Laryngoscope 110 (2000), 1756-1763.

[98] P. Crow, N. Stone, C.A. Kendall, J.S. Uff, A.M. Farmer, H. Barr et al., The use of Raman spectroscopy to identify and grade prostatic adenocarcinoma in vitro, Br. J. Cancer. 89 (2003), 106-108.

[99] Y.N. Yeni, J. Yerramshetty, O. Akkus, C. Pechey and C.M. Les, Effect of fixation and embedding on Raman spectroscopic analysis of bone tissue, Calcif. Tissue Int. 78 (2006), 363-371.

[100] H.P. Buschman, J.T. Motz, G. Deinum, T.J. Römer, M. Fitzmaurice, J.R. Kramer, A. Laarse, A.V. Bruschke and M.S. Feld, Diagnosis of human coronary atherosclerosis by morphology-based Raman spectroscopy, Cardiovasc. Pathol. 10 (2001), 59-68.

[101] G. Shetty, C. Kendall, N. Shepherd, N. Stone and H. Barr, Raman spectroscopy: elucidation of biochemical changes in carcinogenesis of oesophagus, Br. J. Cancer 94 (2006), 1460-1464.

[102] A.S. Haka, Z. Volynskaya, J.A. Gardecki, J. Nazemi, J. Lyons, D. Hicks, M. Fitzmaurice, R.R. Dasari, J.P. Crowe and M.S. Feld, In vivo margin assessment during partial mastectomy breast surgery using Raman spectroscopy, Cancer Res. 66 (2006), 3317-3322.

[103] G. Zhang, D.J. Moore, R. Mendelsohn and C.R. Flach, Vibrational microspectroscopy and imaging of molecular composition and structure during human corneocyte maturation, J. Invest. Dermatol. 126 (2006), 1088-1094.

[104] S. Koljenovic, T.B. Schut, A. Vincent, J.M. Kros and G.J. Puppels, Detection of meningioma in dura mater by Raman spectroscopy, Anal. Chem. 77 (2005), 7958-7965.

[105] R. Malini, K. Venkatakrishna, J. Kurien, K.M. Pai, L. Rao, V.B. Kartha and C.M. Krishna, Discrimination of normal, inflammatory, premalignant, and malignant oral tissue: a Raman spectroscopy study, Biopolymers 81 (2006), 179-193. 
[106] G.V. Nogueira, L. Silveira, A.A. Martin, R.A. Zangaro, M.T. Pacheco, M.C. Chavantes and C.A. Pasqualucci, Raman spectroscopy study of atherosclerosis in human carotid artery, J. Biomed. Opt. 10 (2005), 031117.

[107] A.P. Oliveira, R.A. Bitar, L. Silveira, R.A. Zangaro and A.A. Martin, Near-infrared Raman spectroscopy for oral carcinoma diagnosis, Photomed. Laser Surg. 24 (2006), 348-353.

[108] D.P. Lau, Z. Huang, H. Lui, D.W. Anderson, K. Berean, M.D. Morrison, L. Shen and H. Zeng, Raman spectroscopy for optical diagnosis in the larynx: preliminary findings, Lasers Surg. Med. 37 (2005), 192-200.

[109] C.M. Krishna, G.D. Sockalingum, L. Venteo, R.A. Bhat, P. Kushtagi, M. Pluot and M. Manfait, Evaluation of the suitability of ex vivo handled ovarian tissues for optical diagnosis by Raman microspectroscopy, Biopolymers 79 (2005), 269-276.

[110] C. Krafft, S.B. Sobottka, G. Schackert and R. Salzer, Near infrared Raman spectroscopic mapping of native brain tissue and intracranial tumors, Analyst 130 (2005), 1070-1077.

[111] P. Crow, A. Molckovsky, N. Stone, J. Uff, B. Wilson and L.M. WongKeeSong, Assessment of fiberoptic near-infrared raman spectroscopy for diagnosis of bladder and prostate cancer, Urology 65 (2005), 1126-1130.

[112] A. Shen, Y. Ye, X. Wang, C. Chen, H. Zhang and J. Hu, Raman scattering properties of human pterygium tissue, J. Biomed. Opt. 10 (2005), 024036.

[113] C. Krafft, L. Neudert, T. Simat and R. Salzer, Near infrared Raman spectra of human brain lipids, Spectrochim. Acta A Mol. Biomol. Spectrosc. 61 (2005), 1529-1535.

[114] W.E. Katzin, J.A. Centeno, L.J. Feng, M. Kiley and F.G. Mullick, Pathology of lymph nodes from patients with breast implants: a histologic and spectroscopic evaluation, Am. J. Surg. Pathol. 29 (2005), 506-511.

[115] J. Choi, J. Choo, H. Chung, D.G. Gweon, J. Park, H.J. Kim, S. Park and C.H. Oh, Direct observation of spectral differences between normal and basal cell carcinoma (BCC) tissues using confocal Raman microscopy, Biopolymers 77 (2005), 264-272.

[116] Z. Huang, A. McWilliams, H. Lui, D.I. McLean, S. Lam and H. Zeng, Near-infrared Raman spectroscopy for optical diagnosis of lung cancer, Int. J. Cancer. 107 (2003), 1047-1052.

[117] D.C.G. de Veld, T.C. Bakker Schut, M. Skurichina, M.J.H. Witjes, J.E. Van der Wal, J.L.N. Roodenburg and H.J.C.M. Sterenborg, Autofluorescence and Raman microspectroscopy of tissue sections of oral lesions, Lasers Med. Sci. 19 (2005), 203-209.

[118] N. Stone, C. Kendall, N. Shepherd, P. Crow and H. Barr, Near-infrared Raman spectroscopy for classification of epithelial precancers and cancers, J. Raman Spectrosc. 33 (2002), 564-573.

[119] W.F. March and N.J. Bauer, Non-invasive measurement of corneal hydration, J. Refract. Surg. 17 (2001), S205-210.

[120] S.Y. Lin, S.M. Lee, C.L. Cheng and R.C. Liang, Effect of diabetic duration on the secondary structures of the human lens capsules in diabetic cataracts, Biochem. Biophys. Res. Commun. 216 (1995), 183-189.

[121] S.Y. Lin, S.M. Lee, C.L. Chen and R.C. Liang, Progressive changes in secondary conformation and composition of the senile cataractous human lens capsules, Acta Ophthal. Scan. 74 (1996), 542-546.

[122] S.M. Lee and S.Y. Lin, Differentiation of the maturity of cataractous human lens capsules according to changes in protein secondary structures determined by Fourier-transformed infr ared spectroscopy, Austra. New Zeal. J. Ophthal. 25 (1997), 233-238.

[123] S.M. Lee, S.Y. Lin, C.L. Cheng and R.C. Liang, Possible changes in secondary structure and composition of human lens capsules in Hereditary congenital cataract, Graefe's Arch. Clin. Exp. Ophth. 234 (1996), 342-348.

[124] S.M. Lee, S.Y. Lin, M.J. Li and R.C. Liang, Possible mechanism of accelerating cataract formation in cataractous human lens capsules induced by systemic hypertension or glaucoma, Ophthalmic. Res. 29 (1997), 83-90.

[125] S.Y. Lin, S.M. Lee, M.J. Li and R.C. Liang, Fourier transform infrared spectral evidences for protein conformational changes in immature cataractous human lens capsules accerlerated by myopia and/or systemic hypertension, Spectrochim. Acta A. Mol. Biomol. Spectrosc. 53 (1997), 1507-1513.

[126] S.Y. Lin, M.J. Li, R.C. Liang and S.M. Lee, Nondestructive analysis of the conformational changes in human lens lipid and protein structures of the immature cataracts associated with glaucoma, Spectrochim. Acta A. Mol. Biomol. Spectrosc. 54 (1998), 1509-1517.

[127] K.H. Chen, W.T. Cheng, M.J. Li, D.M. Yang and S.Y. Lin, Calcification of senile cataractous lens determined by FTIR and Raman microspectroscopies, J. Microscop. 219 (2005), 36-41.

[128] C. Rey, B. Collins, T. Goehl, I.R. Dickson and M.J. Glimcher, The carbonate environment in bone mineral: a resolutionenhanced Fourier transform infrared spectroscopy study, Calcif. Tissue Int. 45 (1989), 157-164.

[129] S.Y. Lin, K.H. Chen, M.J. Li, W.T. Cheng and S.L. Wang, Evidence of octacalcium phosphate and type B carbonated apatites deposited on the surface of explanted acrylic hydrogel intraocular lens, J. Biomed. Mater. Res. 70B (2004), 203-208.

[130] K.H. Chen, S.Y. Lin, M.J. Li and W.T. Cheng, Retained antibiotic ophthalmic ointment on an intraocular lens 34 months after sutureless cataract surgery, Am. J. Ophthmal. 139 (2005), 743-745.

[131] K.H. Chen, W.T. Cheng, M.J. Li and S.Y. Lin, Coneal calcification: chemical compositions of calcified deposit, Graefe's Arch. Clin. Exp. Ophthal. 244 (2006), 407-419. 
[132] N. Pleshko, A. Boskey and R. Mendelsohn, Novel infrared spectroscopic method for the determination of crystallinity of hydroxyapatite minerals, Biophys. J. 60 (1991), 786-793.

[133] S.Y. Lin, K.H. Chen, W.T. Cheng and S.L. Wang, Preliminary identification of $\beta$-carotene in the vitreous asteroid bodies by micro-Raman spectroscopy and HPLC analysis, Microsco. Microanal. 13 (2007), in press.

[134] H. Miller, B. Miller, H. Rabinowitz, S. Zonis and I. Nir, Asteroid bodies - An ultrastructural study, Invest. Ophthalmol. Vis. Sci. 24 (1983), 133-136.

[135] J. Winkler and H. Lunsdorf, Ultrastructure and composition of asteroid bodies, Invest. Ophthalmol. Vis. Sci. 42 (2001), 902-907.

[136] H. Komatsu, Y. Kamura, K. Ishi and Y. Kashima, Fine structure and morphogenesis of asteroid hyalosis, Med. Electron. Microsc. 36 (2003), 112-119.

[137] P.S. Bernstein, M.D. Yoshida, N.B. Katz, R.W. McClane and W. Gellermann, Raman detection of macular carotenoids pigments in intact human retina, Invest. Ophthalmol. Vis. Sci. 39 (1998), 2003-2011.

[138] S.Y. Lin, C.W. Wu and R.C. Liang, Effect of ethanol on the protein secondary structure of the human gastric mucosa, in vitro, Eur. J. Clin. Chem. Clin. Biochem. 33 (1995), 255-261.

[139] S.Y. Lin, C.W. Wu, M.J. Li and R.C. Liang, Infra-red (ATR/FT) spectroscopic study on the conformational structure of the isolated human gastric mucus pretreated with ethanol, J. Gastroenterol. Hepatol. 12 (1997), 707-712.

[140] W.T. Cheng, M.T. Liu, H.N. Liu and S.Y. Lin, Micro-Raman spectroscopy used to identify and grade human skin pilomatrixoma, Microscop. Res. Tech. 68 (2005), 75-79.

[141] M.T. Liu, W.T. Cheng, M.J. Li, H.N. Liu, D.M. Yang and S.Y. Lin, Identification of chemical compositions of skin calcified deposit by vibrational microspectroscopies, Arch. Dermatol. Res. 297 (2005), 31-234.

[142] D.B. DeStephano, R.V. Lloyd, A.M. Pike and B.S. Wilson, Pituitary adenomas. An immunohistochemical study of hormone production and chromogranin localization, Am. J. Pathol. 116 (1984), 464-472.

[143] L.S. Lee, S.Y. Lin, C.W. Chi, H.C. Liu and C.L. Cheng, Nondestructive analysis of the protein conformational structure of the human pituitary adenomas by using a reflectance FT-IR microspectroscopy, Cancer Lett. 94 (1995), 65-69.

[144] L.S. Lee, C.W. Chi, H.C. Liu, C.L. Cheng, M.J. Li and S.Y. Lin, Assessment of protein conformation in human benign and malignant astrocytomas by reflectance FT-IR microspectroscopy, Onco. Res. 10 (1998), 23-27.

[145] S.Y. Lin, D.M. Niu, M.J. Li, C.P. Tu and H.L. Lin, Differentiation of hair growth cycle from scalp hair roots for the diagnosis of glucose-6-phosphate dehydrogenase deficiency in neonates, J. Inherit. Metab. Dis. 23 (2000), 693-704.

[146] W. Makalowski, T.G. Wolsberg and I. Makalowska, Genetics of disease, Web. Alert. Curr. Opin. Genet. Dev. 8 (1998), 269-270.

[147] S.Y. Lin, D.M. Niu, C.P. Tu, Y.D. Cheng and H.L. Lin, Evidence of L-cysteinesulfinic acid in PKU neonatal hair roots, with disappearance after dietary control, Ultrastruc. Pathol. 24 (2000), 350-351.

[148] R. Hofestadt and U. Scholz, Information processing for the analysis of metabolic pathways and inborn errors, Biosystems 47 (1998), 91-102.

[149] D.B. Marks, A.D. Marks and C.M. Smith, Synthesis and degradation of amino acids, in: Basic Medical Biochemistry: A Clinical Approach, Williams \& Wilkins, Baltimore, MD, 1996, pp. 595-612.

[150] S.Y. Lin, D.M. Niu, C.P. Tu, H.L. Lin, M.J. Li and Y.D. Cheng, Diagnosis of congenital hypothyroidism from human anagen scalp hair by infrared microspectroscopy, Ultrastruct. Pathol. 25 (2001), 357-360.

[151] P.E. Macchia, M.D. Felice and R.D. Lauro, Molecular genetics of congenital hypothyroidism, Curr. Opin. Genet. Dev. 9 (1999), 289-294.

[152] M.J. Li, H.S. Hsu, R.C. Liang and S.Y. Lin, Infrared microspectroscopic detection of epithelial and stromal growth in the human benign prostatic hyperplasia, Ultrastruct. Pathol. 26 (2002), 365-370.

[153] E. Shapiro, M.J. Becich, V. Hartanto and H. Lepor, The relative proportion of stromal and epithelial hyperplasia is related to the development of symptomatic benign prostate hyperplasia, J. Urol. 147 (1992), 1293-1297.

[154] S.Y. Lin, H.S. Hsu, A.T.L. Lin and R.C. Liang, In vitro simulation of thermotherapy for benign prostatic hyperplasia by Fourier transform infrared microspectroscopy combined with differential scanning calorimetry, Urol. Int. 59 (1997), $161-165$.

[155] S.Y. Lin, H.S. Hsu, R.C. Liang and M.J. Li, Integrality of benign prostatic hyperplasia tissues after transurethral thermotherapy evidenced by transmittance Fourier transform infrared spectroscopy combined with thermal analyzer, Scand. J. Urol. Nephro. 32 (1998), 256-260.

[156] H.S. Hsu, S.Y. Lin, M.J. Li and R.C. Liang, Ultrastructural and biophysical studies on protein conformations of epithelium and stroma in benign prostatic hyperplasia before and after transurethral resection of the prostate, Ultrastruct. Pathol. 26 (2002), 137-141.

[157] J. Nordling, Interstitial cystitis: how should we diagnose it and treat it in 2004?, Curr. Opin. Urol. 14 (2004), $323-327$.

[158] T.Z. Hsieh, K.J. Yu and S.Y. Lin, Possible application of Raman microspectroscopy to verify the interstitial cystitis diagnosis after potassium sensitivity test : Phenylalanine or tryptophan as a biomarker, Disease Marker 23 (2007), in press. 
[159] U. Bindig, H. Winter, W. Wasche, K. Zelianeos and G. Muller, Fiber-optical and microscopic detection of malignant tissue by use of infrared spectrometry, J. Biomed. Opt. 7 (2002), 100-108.

[160] J.T. Motz, M. Fitzmaurice, A. Miller, S.J. Gandhi, A.S. Haka, L.H. Galindo, R.R. Dasari, J.R. Kramer and M.S. Feld, In vivo Raman spectral pathology of human atherosclerosis and vulnerable plaque, J. Biomed. Opt. 11(2) (2006), 021003

[161] F. Adar, G. LeBourdon, J. Reffner and A. Whitley, Raman and FTIR microscopy on a single microscope: Demonstration of the synergism of collecting complementary vibrational spectra from the same spot, Microsco. Microanal. 9 (2003), $1112-1113$.

[162] C.M. Krishna, G. Kegelaer, I. Adt, S. Rubin, V.B. Kartha, M. Manfait and G.D. Sockalingum, Combined Fourier transform infrared and Raman spectroscopic approach for identification of multidrug resistance phenotype in cancer cell lines, Biopolymers 82 (2006), 462-470.

[163] I.W. Levin and R. Bhargava, Fourier transform infrared vibrational spectroscopic imaging: integrating microscopy and molecular recognition, Annu. Rev. Phys. Chem. 56 (2005), 429-474.

[164] M. Jackson, From biomolecules to biodiagnostics: Spectroscopy does it all, Faraday Discussion. 126 (2004), 1-18.

[165] R. Sahu and S. Mordechai, Fourier transform infrared spectroscopy in cancer detection, Future Oncol. 1 (2005), 635-647.

[166] S.G. Demos, A.J. Vogel and A.H. Gandjbakhche, Advances in optical spectroscopy and imaging of breast lesions, J. Mammary Gland Biol. Neoplasia 11 (2006), 165-181. 


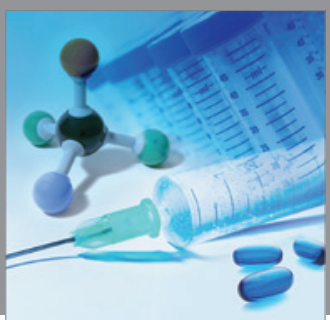

International Journal of

Medicinal Chemistry

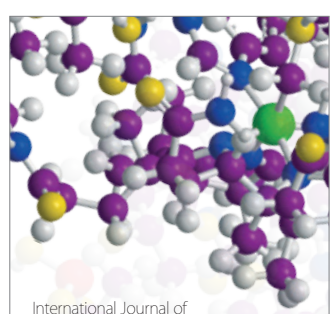

Carbohydrate Chemistry

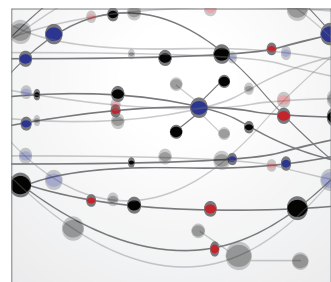

The Scientific World Journal
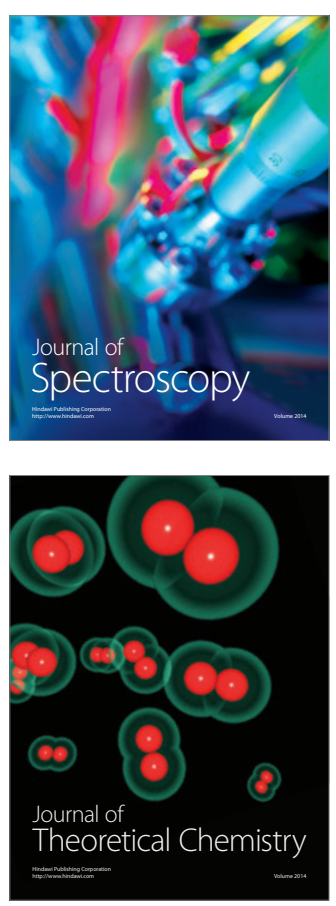
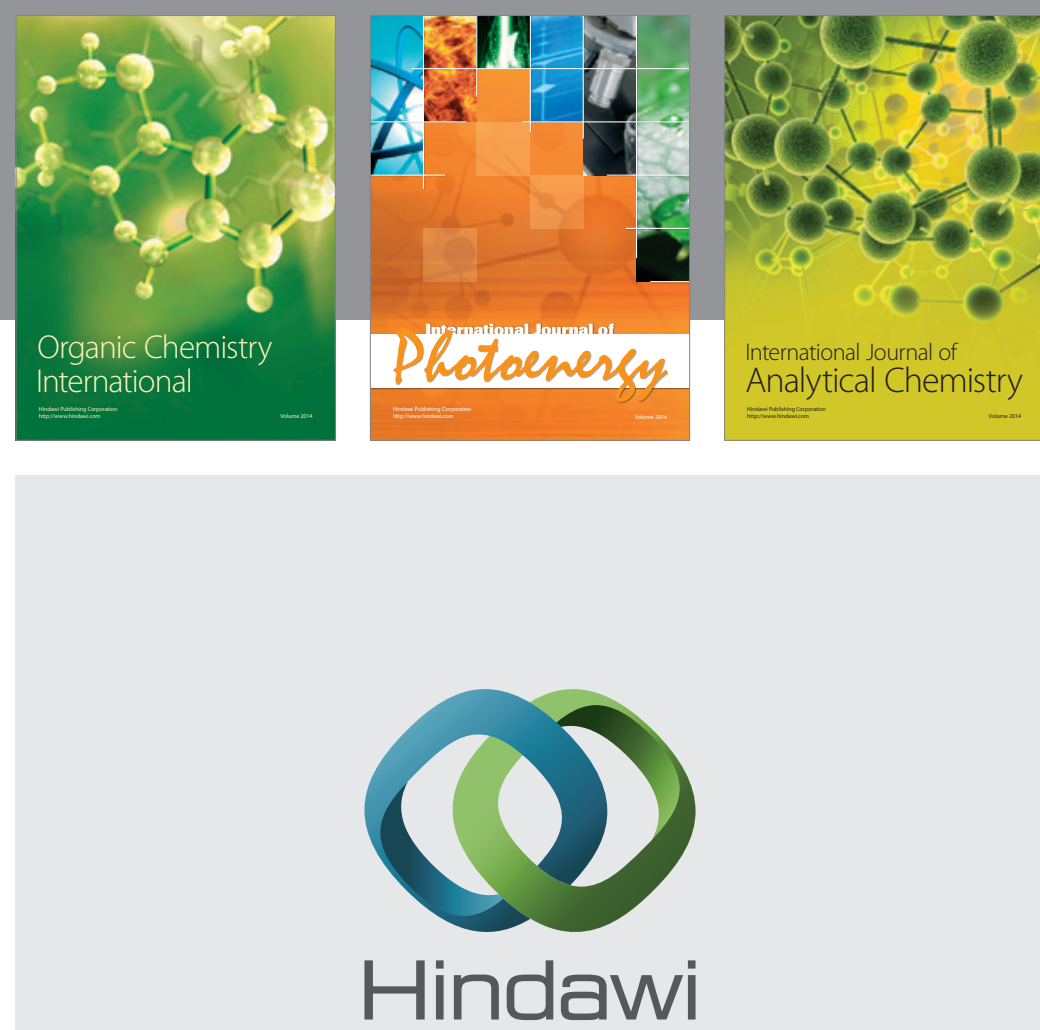

Submit your manuscripts at

http://www.hindawi.com
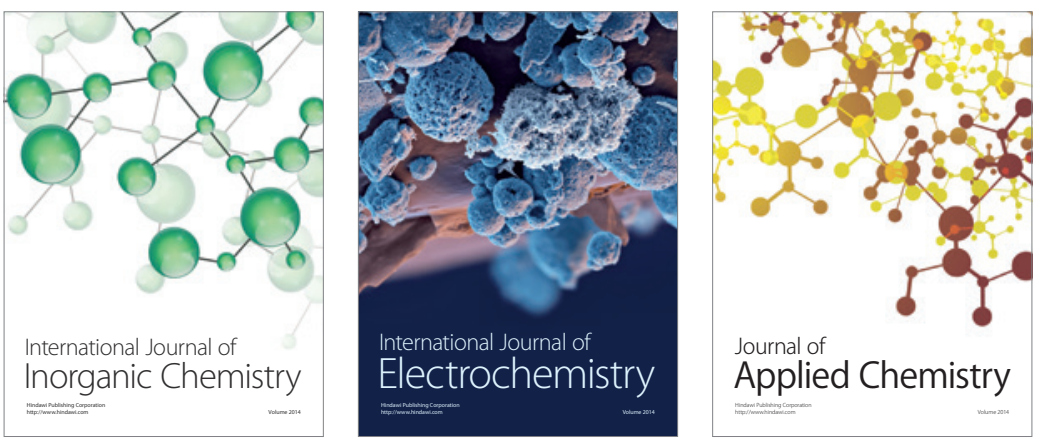

Journal of

Applied Chemistry
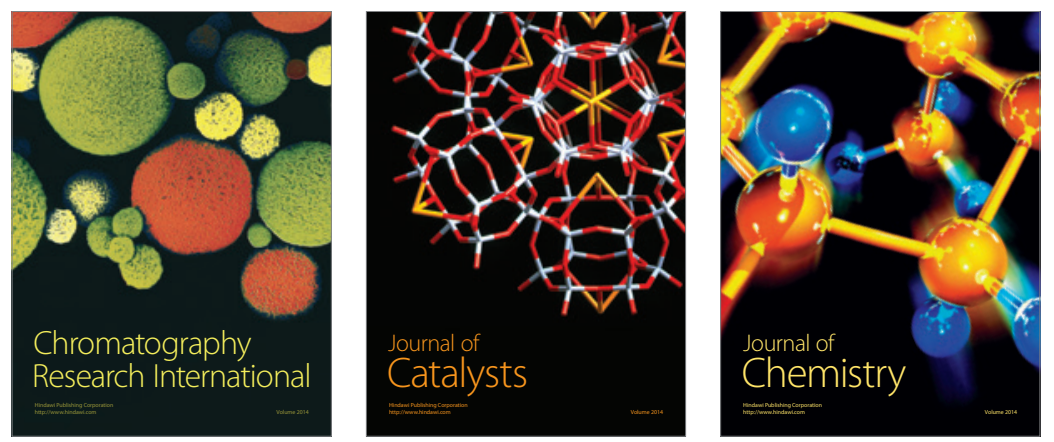
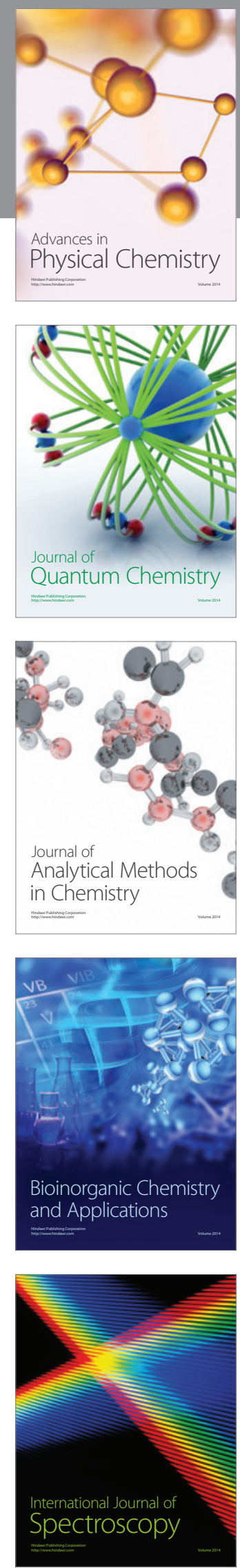